UNIVERSIDADE DE SÃO PAULO

ESCOLA DE ENFERMAGEM

JOSÉ GILBERTO PRATES

\begin{abstract}
AVALIAÇÃO DAS ATITUDES DOS
PROFISSIONAIS DE CENTROS DE ATENÇÃO

PSICOSSOCIAL EM ÁLCOOL E OUTRAS

DROGAS DO MUNICÍPIO DE SÃO PAULO
\end{abstract}

SÃO PAULO

2016 
JOSÉ GILBERTO PRATES

\section{AVALIAÇÃO DAS ATITUDES DOS PROFISSIONAIS DE CENTROS DE ATENÇÃO PSICOSSOCIAL EM ÁLCOOL E OUTRAS DROGAS DO MUNICÍPIO DE SÃO PAULO}

Tese apresentada ao Programa de Pós-Graduação da Escola de Enfermagem da Universidade de São Paulo para obtenção do título de Doutor em Ciências.

Área de Concentração: Cuidado em Saúde

Orientadora: Prof. $\underline{a}$ Dr. ${ }^{\underline{a}}$ Márcia Aparecida Ferreira de Oliveira 
AUTORIZO A REPRODUÇÃO E DIVULGAÇÃO TOTAL OU PARCIAL DESTE TRABALHO, POR QUALQUER MEIO CONVENCIONAL OU ELETRÔNICO, PARA FINS DE ESTUDO E PESQUISA, DESDE QUE CITADA A FONTE.

Assinatura:

Data:

Catalogação na Publicação (CIP)

Biblioteca "Wanda de Aguiar Horta"

Escola de Enfermagem da Universidade de São Paulo

Prates, José Gilberto

Avaliação das Atitudes dos Profissionais de Centros de Atenção Psicossocial em Álcool e Outras Drogas do Município de São Paulo. São Paulo, 2016.

95p.

Tese (Doutorado) - Escola de Enfermagem da Universidade de São Paulo.

Orientadora: Prof. ${ }^{\text {a }}$ Dr. ${ }^{\text {a }}$ Márcia Aparecida Ferreira de Oliveira

Área de concentração: Cuidado em Saúde

1. Atitudes. 2. Transtornos Relacionados ao Uso de Álcool. 3. Serviços de Saúde Mental. I. Título. 
Nome: José Gilberto Prates

Título: Avaliação das Atitudes dos Profissionais de Centros de Atenção Psicossocial em Álcool e Outras Drogas do Município de São Paulo.

Tese apresentada ao Programa de Pós Graduação em Enfermagem Escola de Enfermagem da Universidade de São Paulo para obtenção do título de Doutor em Ciências.

Aprovado em

Banca Examinadora

Prof. Dr. Instituição:

Julgamento: Assinatura:

Prof. Dr. Instituição:

Julgamento: Assinatura:

Prof. Dr. Instituição:

Julgamento: Assinatura:

Prof. Dr. Instituição:

Julgamento: Assinatura:

Prof. Dr. Instituição:

Julgamento: Assinatura: 
"O amor é eterno - sua manifestação pode modificar-se, mas nunca a sua essência, através do amor vemos as coisas com mais tranquilidade, e somente com essa tranquilidade um trabalho pode ser bem sucedido".

Vicent Van Gogh 


\section{Dedicatória}

Dedico esse trabalho:

Aos usuários dos Serviços de Saúde Mental / álcool e outras drogas que num determinado momento emergencial de suas vidas perderam o controle.

A minha mãe Honorina (in memoriam), o começo de tudo, pelo carinho com que me educou, suas exigências fundamentaram o que eu sou; as minhas irmãs Gilka e Gizelda (in memoriam), que compartilharam minha sobrevivência.

A Roseli minha companheira, amiga e amante que me possibilitou ser pai da Dani e do Du meus amores incondicionais. 


\section{Agradecimentos}

A Deus, pelas oportunidades, por ser meu refúgio, minha fortaleza nas horas difíceis e pela fonte inesgotável de luz.

Agradecimento especial, minha querida orientadora Prof ${ }^{\mathbf{a}}$ Dra $^{\mathbf{a}}$ Márcia Aparecida Ferreira de Oliveira ; Nesses anos de convivência, acolhimento a todos sem distinção.

Sua dedicação, serenidade, disponibilidade, tem me ajudado a superar os desafios desse percurso; você é especial para todos nós pelo seu jeito amigo, de ser. 'Alma iluminada

Gosto muito de ti e não há palavras para agradecer todo o incentivo, toda a compreensão, o carinho que tens para comigo, propiciando a concretização de mais uma etapa de minha vida; muito obrigado.

Agradecimento especial, também à Profa ${ }^{a}$ Dra ${ }^{a}$ Heloísa Garcia Claro pela atenção, carinho, disponibilidade, suas orientações foram preciosas nessa construção de saberes ; muito obrigado

Agradecimento especial, também à minha amiga Profa ${ }^{\text {. Dra }}$ Paula Hayasi Pinho que compartilhou essa caminhada lado a lado comigo, pela atenção, carinho, disponibilidade, você foi muito importante nessa construção de saberes ; muito obrigado

Ao Prof Dr. Divane de Vargas, pela construção da (EAFAAA) Escala de Atitudes frente ao Álcool, ao Alcoolismo e ao Alcoolista, pelo carinho que tem dedicado a todos os alunos da EEUSP que o procura, sua sabedoria, apoio e incentivo me ajudaram muito neste caminhar 
e me deram a oportunidade de aprender com suas experiências desde o início desta trajetória, durante a qualificação e até o presente momento; além de seu jeito feliz de acolher a todos; o meu muito obrigado.

Ao Prof $^{\circ}$ Dr $^{\circ}$ Ivan Fernandes; Pela participação nessa pesquisa e principalmente pelo acolhimento e amizade, muito obrigado.

A Prof ${ }^{a}$ Dra Sonia Barros; pelo apoio na minha carreira como enfermeiro.

A Prof ${ }^{\mathrm{a}}$ Dra Ana Luisa Aranha e Silva; pelo apoio no início de minha carreira como enfermeiro, sempre me orientando a contextualizar as práticas de assistir o outro e entender a teia da reforma e das políticas de saúde mental.

A Prof ${ }^{a}$ Dra Marina Borges Teixeira; pela sabedoria. Apoio e incentivo desde meus primeiros passos como enfermeiro; sou muito grato pela oportunidade de aprender com suas experiências, durante vários anos de convivências.

A Prof ${ }^{a}$ Dra $^{\text {a }}$ Maguida Costa Stefanelli; pela sabedoria, apoio e incentivo; sou muito grato pela oportunidade de aprender com suas experiências, durante vários anos de convivências.

A Prof ${ }^{a}$ Ms Zélia Nunes Hupsel; pelos primeiros ensinamentos do significado de ser um enfermeiro psiquiátrico.

A Prof ${ }^{\text {a }}{ }^{\text {a }}$ Maria Júlia Paes da Silva; como esquecer que comunicação tem remédio.

A eterna professora Hideko Takeuchi Forcella (in memoriam); como disse o amigo Mafú, você eternizou em nossos corações; um abraço e muito obrigado.

Aos professores da EEUSP; em especial àqueles do Departamento de Enfermagem Materno-Infantil e Psiquiátrica (ENP) que com 
dedicação se empenham em tornar novos profissionais e possibilitam a contínua construção de novos saberes

Prof ${ }^{a}$ Dr ${ }^{a}$ Ana Lucia Machado, Prof ${ }^{a}$ DráLuciana de Almeida Couvero,

Prof ${ }^{\mathrm{a}}$ Dra $^{\mathrm{a}}$ Maria do Perpétuo Socorro; pela oportunidade da convivência, pelo apoio, pelas conversas e pelo carinho nesses anos de travessia na Saúde Mental.

A todos colegas do GEAD; Prof ${ }^{\mathrm{a}} \mathrm{Dr}^{\mathrm{a}}$ Maria Odete, Profo ${ }^{-} \mathrm{Dr}$ Guilherme, Prof Dra ${ }^{a}$ Sonia Paiva, Dra Regiane, Ricardo, Thaís, Rosana, Fúlvia, e a todos do grupo....

Ao Prof. Dr Francisco Lotufo Neto pelo apoio ao meu trabalho frente à Residência de Enfermagem e Aprimoramento IPQ - HCFMUSP.

Ao Prof. Dr. Arthur Guerra de Andrade e toda a equipe do GREA pelo acolhimento tanto na disciplina como no grupo de atendimento do Ambulatório.

Ao Prof.Dr André Malbergier; pelas orientações no exame de qualificação dessa pesquisa, suas considerações trouxe-me a reflexão de como escrever essa construção.

Ao Prof. Dr Homero Pinto Vallada Filho pelo acolhimento e ensino na sua disciplina de pós da FMUSP.

A Prof ${ }^{\mathrm{a}}$ Dra Alexandrina Maria Augusto da Silva Meleiro pelas orientações e incentivo por sempre acreditar no meu trabalho; muito obrigado.

A Diretoria Executiva do Instituto de Psiquiatria do HC - FMUSP; representado pelo Dro Luciano Eduardo Maluf Patah

A Divisão de Enfermagem do Instituto de Psiquiatria do HC - FMUSP representado pela Diretora de enfermagem Solange Regina Giglioli Fusco. 
A Unidade Educação Permanente do IPQ - HC - FMUSP em especial ; A Dra Edna Rodrigues (in memoriam); pelas orientações no meu caminhar profissional, principalmente, na Educação Permanente; Tânia Regina, Lacy Marques e Gizele de Oliveira; muito obrigado.

Ao escritório de projetos do IPQ - HCFMUSP; representado pela Aline Fernanda Pedrazzi; pelas oportunidades de participar dos vários projetos de ensino.

A Coordenação de Ensino e da Residência Multiprofissional do GREA representados por Dro Ricardo Abrantes do Amaral, Prof ${ }^{\mathrm{a}}$ Dr $^{\mathrm{a}}$ Elisabete Ferreira Mângia; Prof ${ }^{\mathrm{a}}$ Ms Aniara Correa pela oportunidade dos vários projetos acadêmicos.

A todos os colegas do Instituto de Psiquiatria do HC - FMUSP; em especial os enfermeiros, técnicos, auxiliares e escriturários da Divisão de enfermagem, que compartilham minhas vivências no trabalho; muito obrigado.

Aos meus amigos especiais; Alexandre C. Zolnner, Cristina Emiko Igue, Jouce Gabriela de Almeida, Varlene, lara, Dinah, Rafaela, Márcia, Conceição, Sandra, Lilian, Itamar.....

A minha enfermeira espiritual Norma você nasceu para cuidar das pessoas muito obrigado por tudo.

Ao meu amigo espiritual, Daniel você me faz feliz.

A todos os pacientes que tive a oportunidade de cuidar, razão do meu crescimento como profissional e como pessoa; muito obrigado.

A todos que de algum modo contribuíram para essa conquista; muito obrigado. 


\section{Epígrafe}

\section{Atitude:}

É uma norma de procedimento que leva a um determinado comportamento.

É a concretização de uma intenção ou propósito.

De acordo com a psicologia, a atitude é comportamento habitual que se verifica em circunstâncias diferentes.

As atitudes determinam a vida anímica de cada indivíduo.

As atitudes são patenteadas através das reações repetidas de uma pessoa.

Este termo tem particular aplicação no estudo do caráter, como indicação inata ou adquirida, relativamente estável, para sentir e atuar de uma forma determinada.

Nessa pesquisa especificamente retrataremos das atitudes de profissionais da saúde mental, que trabalham com dependentes de substâncias psicoativas em CAPSad, que podem apresentar uma esfera tanto positiva quanto negativa,

As determinantes para as atitudes dos profissionais da saúde são construções que independem apenas do caráter do homem profissional, e sim de como este olha o mundo $e$ qual a representação e significância que seu trabalho tem ou terá no decorrer de sua vida profissional.

Esse trabalho tem a intencionalidade maior de contribuir com novas reflexóes sobre atitudes positivas na educação permanente dos trabalhadores da saúde mental em especial aos que atendem dependentes de substâncias psicoativas. 
Prates, JG. Avaliação das Atitudes dos Profissionais de Centros de Atenção Psicossocial em Álcool e Outras Drogas do Município de São Paulo [tese]. São Paulo: Escola de Enfermagem, Universidade de São Paulo; 2015.

\section{RESUMO}

Este estudo tem por objetivo avaliar em uma amostra de 12 CAPSad da cidade de São Paulo as atitudes dos profissionais desses serviços frente ao álcool, alcoolismo e alcoolista. Trata-se de uma pesquisa que utiliza métodos quantitativos transversais, descritivos e exploratórios. De um total de 349 trabalhadores cadastrados, 288 foram localizados e entrevistados (perda de 17,4\%). Para o presente estudo foi utilizado um questionário de dados sócio demográficos, as Escalas de Satisfação SATIS-BR e a Escala de Atitudes frente ao álcool, alcoolismo e alcoolista - EAFAAA. Foi realizada análise descritiva dos dados, testes para a média e cálculos dos intervalos de confiança para cada uma das variáveis quantitativas. Para verificar as associações entre as variáveis foram realizados modelos de regressão de mínimos quadrados ordinários (Ordinary Least Squares - OLS) univariadas e múltiplas. No presente estudo foi definido como variável dependente o escore de Atitudes Frente ao Álcool, Alcoolismo e Alcoolista, medida pelo escore da EAFAAA (varia de forma contínua de 1 a 5 ). Os resultados sugerem que profissionais mais críticos com o seu cotidiano de trabalho apresentam tendência a atitudes positivas frente ao álcool, ao alcoolismo e ao alcoolista, o que pode estar relacionado ao fato desses profissionais se apropriarem da dinâmica existente nos CAPSad, questionando incoerências técnicas, a gestão e a organização do serviço, bem como o seu processo de trabalho. Profissionais mais críticos, 
reflexivos, que tiveram acesso ao conteúdo relacionado ao uso de álcool e outras drogas em seus cursos de formação profissional, e que possuem mais experiência de trabalho possuem atitudes mais positivas frente ao álcool, alcoolismo e alcoolista. Esses resultados apontam para a necessidade de investimentos em educação, tanto nos cursos básicos, técnicos e de graduação, quanto em educação permanente nos serviços.

DESCRITORES: Avaliação de Serviços de Saúde, Transtornos Relacionados ao Uso de Álcool, Transtornos Relacionados ao Uso de Substâncias, Serviços de Saúde Mental. 
Prates, JG. Evaluation of Attitudes of Mental Health Services Professionals on Alcohol and Other Drugs in the Municipality of São Paulo [thesis]. São Paulo: School of Nursing, University of São Paulo; 2015.

\section{ABSTRACT}

This study aims to evaluate in a sample of 12 CAPSad of the municipality of São Paulo the attitudes of the professionals of these services towards of alcohol, alcoholism and alcohol addicts. This research uses cross-sectional, descriptive and exploratory quantitative methods. From a population of 349 registered workers, 288 were located and interviewed (loss of 17.4\%). For the present study, it was used a questionnaire for socio demographic data, Satisfaction Scales SATIS - BR and an Attitude Scale towards alcohol, alcoholism and alcohol addicts - EAFAAA. It was performed a descriptive analysis of the data, tests of means and the calculation of confidence intervals for each of the quantitative variables. To verify the associations among variables, it was made a series of ordinary least squares regression models (OLS) for both univariate and multiple analysis. It was defined as the dependent variable the score Attitudes towards alcohol, alcoholism and alcohol addicts, measured by the score of EAFAAA (varies continuously from 1 to 5$)$. The results suggest that the most critical professionals with their daily work have a tendency to have positive attitudes towards alcohol, alcoholism and alcoholics, which may be related to the fact that these professionals appropriate of the existing dynamics in CAPSad, questioning techniques inconsistencies, the management and organization of the service, as its work process. Practitioners that are more critical, thoughtful, who had access to content related to alcohol and other drugs in its training courses, and that have more 
work experience have more positive attitudes towards alcohol, alcoholism and alcohol addicts. These results point to the need for investment in education, both in basic courses, technical and graduation, as in continuing education in services

DESCRIPTORS: Health Services Evaluation, Alcohol-Related Disorders, Substance-Related Disorders, Mental Health Services. 


\section{LISTA DE TABELAS}

Tabela 1: Natureza dos Sujeitos da pesquisa por CAPSad. São Paulo/SP ( $n=288)$

Tabela 2: Apresentação das informações sociodemográficas segundo os profissionais de saúde dos CAPSad, São Paulo-SP $(\mathrm{n}=288) \quad 52$

Tabela 3: Escores obtidos na EAFAAA, global e em seus fatores $(\mathrm{n}=229)$.

Tabela 4: Condições e incômodos enfrentados no trabalho pelos profissionais dos CAPSad, São Paulo/SP ( $\mathrm{n}=288)$.

Tabela 5: Visão do trabalhador acerca de sua autonomia no trabalho - Possibilidades de trabalho no CAPSad, São Paulo/SP $(\mathrm{n}=288) . \quad 57$

Tabela 6: Médias e desvios padrão do Escore Global e de cada fator da escala SATIS-BR, segundo os profissionais dos CAPSad, São Paulo/SP ( $\mathrm{n}=288)$.

Tabela 7: Visão dos trabalhadores sobre a razão principal para 0 tratamento e abordagem utilizada no CAPSad. .............................. 59

Tabela 8: Modelos univariados para atitudes dos profissionais. .....61 61

Tabela 9: Modelo múltiplo para atitudes dos profissionais 63 


\section{LISTA DE FIGURAS}

Figura 1: Fluxograma da participação dos sujeitos de pesquisa. 41

Figura 2: Estimativa de densidade de kernel para atitudes trabalhadores. 


\section{LISTA DE SIGLAS}

\begin{tabular}{|c|c|}
\hline AOD & Álcool e outras Drogas \\
\hline APS & Atenção Primária à Saúde \\
\hline CAPSad & $\begin{array}{l}\text { Centro de Atenção Psicossocial Álcool e outras } \\
\text { Drogas }\end{array}$ \\
\hline CMSM & Coordenação Municipal de Saúde Mental \\
\hline EAFAAA & $\begin{array}{l}\text { Escala de Atitudes frente ao Álcool, Alcoolismo e } \\
\text { Alcoolista }\end{array}$ \\
\hline EEUSP & $\begin{array}{l}\text { Escola de Enfermagem da Universidade de São } \\
\text { Paulo }\end{array}$ \\
\hline EMP & Escala de Mudança Percebida \\
\hline GEADEEUSP & $\begin{array}{l}\text { Grupo de Estudos em Álcool e outras Drogas da } \\
\text { Escola de Enfermagem da Universidade de São } \\
\text { Paulo }\end{array}$ \\
\hline MS & Ministério da Saúde \\
\hline NASF & Núcleo de Atenção à Saúde da Família \\
\hline OLS & Ordinary Least Squares \\
\hline OMS & Organização Mundial da Saúde \\
\hline os & Organização Social \\
\hline PT & Portaria \\
\hline PTI & Projeto Terapêutico Institucional \\
\hline PTS & Projeto Terapêutico Singular \\
\hline RAPS & Rede de Atenção Psicossocial \\
\hline RAS & Rede de Atenção à Saúde \\
\hline RL & Redução de Danos \\
\hline
\end{tabular}


SATIS-BR Escala de Avaliação da Satisfação em Serviços de Saúde Mental

SMS Secretaria Municipal da Saúde

SUS Sistema Único de Saúde

UBS Unidade Básica de Saúde

WHO World Health Organization

CNSM Conferência Nacional de Saúde Mental 


\section{SUMÁRIO}

1 INTRODUÇÃO

1.2 Políticas de atenção ao usuário de álcool e outras drogas

1.3 Os Centros de Atenção Psicossocial em Álcool e outras Drogas (CAPSad) ........................................................... 29

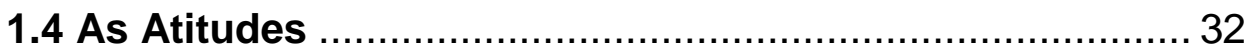

1.5 ATITUDES FRENTE AO ÁlCOOL, ALCOOLISMO E O

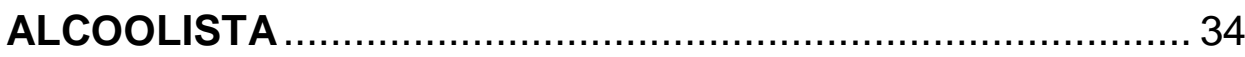

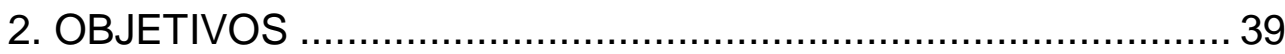

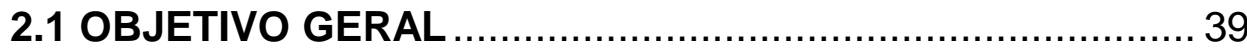

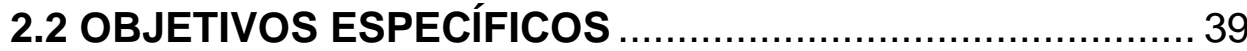

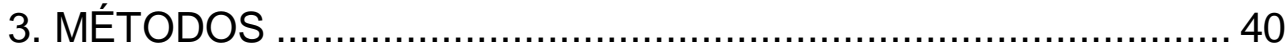

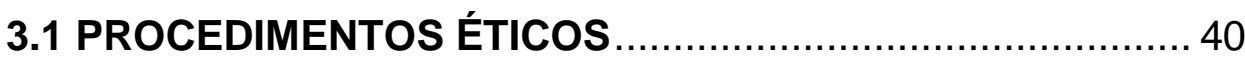

3.4 PERÍODO DE REALIZAÇÃO DO ESTUDO E LOCAIS ONDE

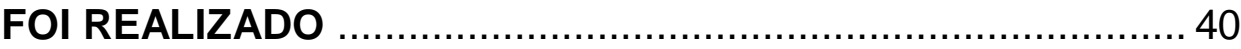

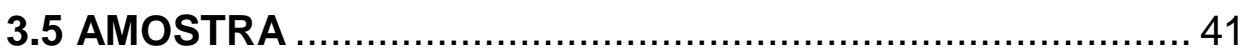

3.6 CRITÉRIOS PARA INCLUSÃO E EXCLUSÃO DE

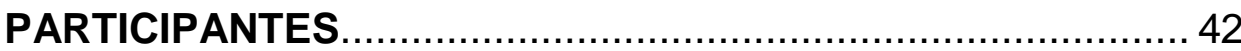

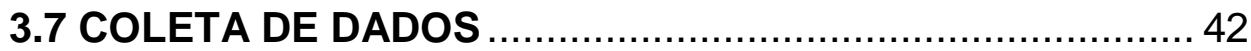

3.8 INSTRUMENTOS DE COLETA DE DADOS ........................ 43

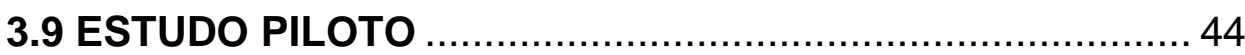

3.10 TRATAMENTO E ANÁLISE DOS DADOS …...................... 46

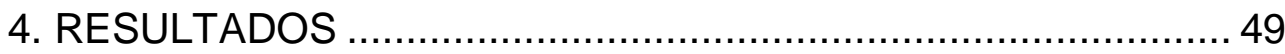

4.1 ANÁLISE DESCRITIVA - PERFIL DOS SUJEITOS DE

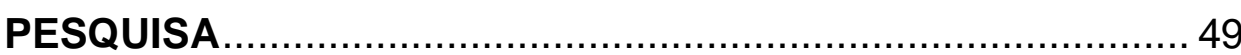

4.1.1 Caracterização dos Profissionais dos CAPSad de São

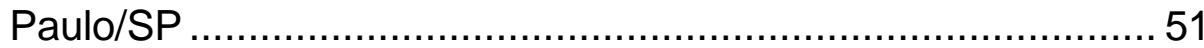

4.1.2 Caracterização das Atitudes dos Profissionais dos CAPSad de São Paulo............................................................... 54

4.2 ANÁLISE DESCRITIVA ......................................... 56

4.2.1.1 O CAPSad na Perspectiva dos Profissionais dos CAPSad de São Paulo/SP 


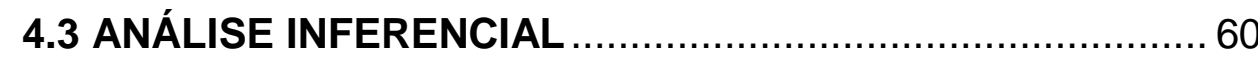

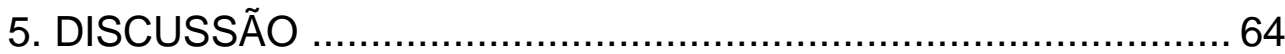

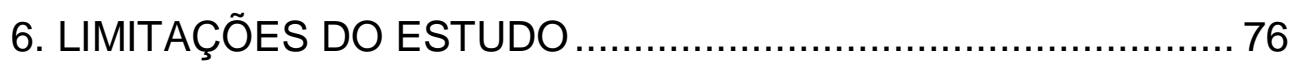

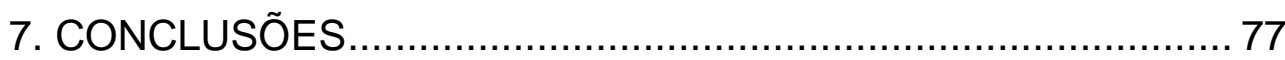

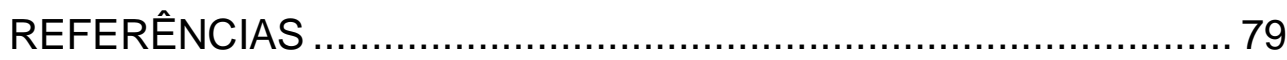

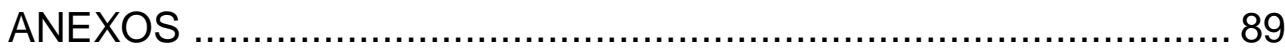

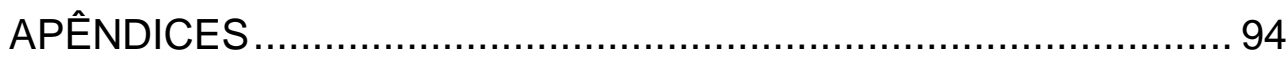




\section{INTRODUÇÃO}

\subsection{Dados epidemiológicos}

O uso abusivo e a dependência de Substâncias Psicoativas (SPAS) é um problema grave que atinge a saúde pública no Brasil e no mundo. O círculo vicioso tanto das drogas lícitas como das ilícitas envolve danos biológicos, psicológicos, sociais, econômicos, culturais, ético-legais e morais.

Segundo a WHO (2014) a prevalência do uso de drogas no mundo tem se mantido estável, cerca de 243 milhões de pessoas, ou $5 \%$ da população global entre 15 e 64 anos de idade, consumiram drogas ilícitas em 2012. Em relação aos usuários de SPAS dependentes, estes somam por volta de 27 milhões, aproximadamente $0,6 \%$ da população adulta mundial, ou 1 em cada 200 pessoas $^{1}$.

Ainda em relação às drogas ilícitas, entre 2003 e 2012, observou-se que países como a África, Oceania e as Américas ocorreu maior consumo de substâncias derivadas da cannabis. A proporção de internações para tratamento dessa substância aumentou na Europa, América Latina, Caribe e Oceania ${ }^{1}$.

A maior demanda para o tratamento da dependência de opióides ocorre no Sudeste da Europa Oriental e da Ásia, enquanto nas Américas, principalmente América Latina e Caribe, a maior procura por tratamento ocorre para o uso de cocaína e derivados, como o crack ${ }^{1}$.

No que se refere à substância legal mais consumida mundialmente - o álcool, a WHO (2014) estima que cerca de 3,3 milhões de pessoas morreram no ano de 2012, em todo o mundo, em consequência do consumo nocivo de álcool. Os números equivalem a 5,9\% de todas as mortes, sendo superior à mortalidade ligada ao HIV $(2,8 \%)$, à violência $(0,99 \%)$ e à tuberculose $(1,7 \%)$. 
Mais de 200 tipos de doenças e lesões mantém relação causal com o consumo abusivo do álcool. A cirrose, o câncer e as desordens mentais e comportamentais estão comumente associadas ao uso do álcool ${ }^{2}$.

Grande parte das lesões fatais decorrentes do uso nocivo do álcool ocorre em grupos etários relativamente jovens, o que se traduz como perda de pessoas economicamente ativas, aquelas que se encontram na faixa etária de 20 a 39 anos ${ }^{2}$.

O consumo mundial total de álcool é de aproximadamente $46 \%$ de bebidas destiladas, $36 \%$ de cerveja, $9 \%$ de vinho e $10 \%$ de outras bebidas. Entretanto, há diferenças geográficas que influenciam o tipo de bebida alcoólica mais consumida em cada país. O vinho, por exemplo, é a bebida mais consumida em países do norte europeu, na Suécia e nos países sul-americanos (Argentina e Chile). Na África Subsaariana consome-se vinho, cerveja e destilados. No norte europeu e no restante do mundo consome-se mais cerveja ${ }^{2}$.

Em relação aos dados epidemiológicos nacionais, o Centro Brasileiro de Informações sobre Drogas Psicotrópicas (CEBRID) realizou duas pesquisas domiciliares de caráter nacional em 107 cidades brasileiras, com população superior a 200.000 habitantes na faixa etária compreendida entre 12 e 65 anos, nos anos de 2001 e $2005^{3}$

A comparação entre as pesquisas demonstrou um agravamento nos indicadores de uso de álcool. No I Levantamento Domiciliar a prevalência de dependência de álcool foi de 11,2\% na população geral, enquanto no II Levantamento foi de 12,34

O aumento do consumo de álcool em faixas etárias cada vez mais precoces também foi evidenciado pelos dados. Em 2001, o número de dependentes na faixa de 12 a 17 anos foi de $5,2 \%$ contra $7 \%$ em $2005^{4}$ 
Corroborando com os dados acima, pesquisa realizada entre os escolares nas capitais brasileiras e Distrito Federal indicou que cerca de três quartos dos adolescentes, de 13 a 15 anos, já experimentaram álcool, cerca de um quarto bebeu regularmente nos últimos 30 dias com episódios de embriaguez e 9\% relatam ter tido problemas com o álcool. Quanto às drogas, 8,7\% relataram já ter experimentado estas substâncias alguma vez na vida, sendo que a experimentação do álcool e drogas ocorreu muito precocemente ${ }^{5}$.

O maior número de dependentes de bebidas alcoólicas continua sendo do sexo masculino na faixa etária entre 18 e 24 anos, o percentual foi de $23,7 \%$ (2001) e $27,4 \%(2005)^{4}$

Segundo dados do Relatório da OMS o Brasil está acima da média mundial em consumo de bebidas alcoólicas e consumiu 8,7 litros de álcool por ano, entre 2008 e 2010. A média mundial foi de 6,2 litros ${ }^{2}$.

Estudos e Inquéritos que utilizaram dados secundários de mortalidade, principalmente em países desenvolvidos, indicam que há maiores oportunidades para consumo e mais consumidores com padrões de consumo de baixo risco nos grupos socioeconômicos mais elevados, enquanto a abstenção é maior nos grupos sociais menos favorecidos. Entretanto, a população que possui pior nível socioeconômico é mais vulnerável aos problemas e consequências do consumo abusivo do álcool ${ }^{6}$.

Apesar dos dados epidemiológicos evidenciarem o aumento da quantidade e do consumo de álcool em faixas etárias cada vez mais jovens, concordamos com a WHO que o álcool é considerado um tema de prioridade relativamente baixa nas políticas públicas, incluindo as de saúde, apesar da elevada carga social, sanitária e econômica associada ao consumo nocivo ${ }^{2}$.

No Brasil ocorreram importantes avanços nas políticas de controle do tabagismo e os resultados positivos são evidentes ${ }^{7}$. 
Entretanto, observamos pouca evolução nas políticas voltadas à redução do consumo nocivo do álcool.

Embora se reconheça que as políticas públicas constituem a estratégia mais bem-sucedida para 0 enfrentamento do problema relacionado ao álcool 5 . A autora exemplifica a "Lei Seca" (Lei no $11.705 / 2008)^{8}$, como uma estratégia de sucesso, que resultou na diminuição de mortes por acidentes de trânsito um ano após a vigência da lei.

Com o fim de alcançar uma mudança política e uma maior conscientização sobre a necessidade do combate ao consumo nocivo do álcool, em âmbito global, a Assembleia Mundial da Saúde aprovou, em 2012, uma meta de redução de $25 \%$ na mortalidade prematura por Doenças Crônicas Não Transmissíveis (DCNT) entre os anos de 2015 e 2025, com metas específicas, a serem alcançadas globalmente, relacionadas aos quatro principais fatores de risco para as DCNT: tabagismo, consumo nocivo do álcool, alimentação não saudável e inatividade física ${ }^{5}$.

$\mathrm{Na}$ mesma direção, o Brasil no seu Plano de Ações Estratégicas para o Enfrentamento das DCNT, 2011-2022, inclui entre suas metas a "Redução da prevalência de consumo nocivo de álcool, de $18 \%$ (2011) para $12 \%$ em (2022)" 5 .

Considerando os dados acima e os diversos prejuízos advindos do uso abusivo de SPAS, estudos nacionais e internacionais tem se debruçado sobre a complexa temática do uso abusivo de álcool e outras drogas seja na área da prevenção, do tratamento ou das políticas públicas de saúde.

\subsection{Políticas de atenção ao usuário de álcool e outras drogas}

Apesar do cenário epidemiológico descrito, no que se refere às estratégias de atenção voltadas para o uso abusivo de SPAS, 
podemos observar que houve uma importante lacuna na história da saúde pública brasileira.

A questão das drogas foi deixada para as instituições da justiça, da segurança pública, da pedagogia, da benemerência e das associações religiosas onde predominavam as "alternativas de atenção" de caráter asilar, baseadas em práticas de natureza medicamentosa, disciplinar ou de cunho religioso-moral, reforçando o isolamento social e o estigma ${ }^{9}$.

Entretanto, as consequências do uso abusivo de álcool e outras drogas como poderosos determinantes para a morbimortalidade, no final do Século XX, trouxeram a discussão do tema para o campo da saúde pública.

Mas foi somente a partir de 2003, que se iniciou uma discussão mais sistemática do tema no campo da saúde pública e entre outros setores, então o MS concebeu um documento sobre a Política do Ministério da Saúde para a Atenção Integral a Usuários de Álcool e Outras Drogas ${ }^{10}$

Este documento contém as diretrizes para uma política e para a estruturação e fortalecimento de uma rede de assistência centrada na atenção comunitária, associada à rede de serviços de saúde e sociais, com ênfase na reabilitação e reinserção dos seus usuários, tendo o território por base.

Destaca ainda que os cuidados oferecidos à população que apresentam problemas decorrentes do uso de álcool e outras drogas devem ser baseados em dispositivos extra-hospitalares de atenção psicossocial, devidamente articulados à rede assistencial em saúde mental e aos demais equipamentos de saúde integrantes da rede.

Estes serviços devem fazer uso deliberado e eficaz dos conceitos de território e rede, bem como da lógica ampliada da concepção da Redução de Danos (RD), operacionalizando uma busca ativa e sistemática das necessidades a serem atendidas, de 
forma integrada ao meio sócio-cultural em que os usuários estiverem inseridos, convergindo necessariamente com os princípios da Reforma Psiquiátrica brasileira ${ }^{10}$.

O ano de 2005 foi marcado por múltiplas iniciativas, sendo criados: mecanismos de financiamento para os leitos destinados aos usuários de álcool e outras drogas nos hospitais gerais (PT MS/GM no 1.612/05) 11, incentivos financeiros para os CAPSad que desenvolvessem ações de Redução de Danos (PT MS/GM n.. $1.059 / 05)^{12}$ e os CAPS I foram autorizados a cobrar do SUS pelos atendimentos às pessoas com transtornos decorrentes do uso de álcool e outras drogas (PT MS/SAS n.. $\left.{ }^{0} 384 / 05\right){ }^{13}$.

Outras iniciativas fora da área da saúde também ocorreram como o Pacto Nacional para Redução de Acidentes e Violência Associados ao Consumo Prejudicial de Álcool e o avanço na área jurídica que aproxima o uso pessoal de drogas a uma questão de saúde pública, afastando-o do âmbito policial ${ }^{14}$.

Com o propósito de garantir a integralidade do cuidado, cujo objetivo é promover a integração sistêmica, de ações e serviços de saúde com provisão de atenção contínua, integral, de qualidade, responsável e humanizada, bem como incrementar o desempenho do Sistema, em termos de acesso, equidade, eficácia clínica e sanitária; e eficiência econômica; mais recentemente, em 2010, o MS criou a Rede de Atenção à Saúde (RAS) ${ }^{15}$.

A RAS pode ser compreendida a partir de arranjos organizativos de ações e serviços de saúde, de diferentes densidades tecnológicas, que integradas por meio de sistemas de apoio técnico, logístico e de gestão, buscam garantir o acesso e a integralidade do cuidado ${ }^{15}$.

A RAS fundamenta-se na compreensão da Atenção Primária à Saúde (APS) como primeiro nível de atenção, destacando a função resolutiva dos cuidados primários sobre os problemas mais comuns 
de saúde e, a partir do qual se realiza e coordena o cuidado em todos os pontos de atenção.

Convergindo com a RAS, especificamente na área da saúde mental, a Portaria no 3088/GM/MS, de 23 de dezembro de 2011, institui a Rede de Atenção Psicossocial (RAPS) para atenção às pessoas com sofrimento ou transtorno mental e com necessidades decorrentes do uso de crack, álcool e outras drogas, no âmbito do SUS ${ }^{16}$.

A RAPS objetiva ampliar o acesso à atenção psicossocial da população em forma geral, promover a vinculação das pessoas com transtornos mentais e com necessidades decorrentes do uso de crack, álcool e outras drogas e suas famílias aos pontos de atenção do sistema e, garantir a articulação e integração dos pontos de atenção das redes de saúde tendo o território por base, qualificando o cuidado por meio do acolhimento, do acompanhamento contínuo e da atenção às urgências ${ }^{16}$.

Cabe destacar que são integrantes da RAPS: Atenção Básica em Saúde, Atenção Psicossocial Especializada, Atenção de Urgência e Emergência, Atenção Residencial de Caráter Transitório, Atenção Hospitalar, estratégias de Desinstitucionalização, Equipes de Consultório na Rua e Reabilitação Psicossocial. 


\subsection{Os Centros de Atenção Psicossocial em Álcool e outras Drogas (CAPSad)}

Neste item apresenta-se o CAPSad que corresponde à principal instituição pública de atenção especializada aos transtornos decorrentes do uso abusivo e/ou dependência de drogas, substitutivo ao hospital psiquiátrico.

Os CAPS e os CAPSad foram implementados seguindo a lógica não manicomial e alternativa para oferecer assistência na área da saúde mental, respeitando e valorizando a perspectiva dos direitos humanos ${ }^{17}$.

Esse serviço surgiu com a necessidade de oferecer um cuidado singular ao usuário de AOD, os CAPS são serviços de atenção psicossocial que se caracterizam pelo cuidado e atenção diária de seus usuários, além do papel de articulador de toda a rede de atenção, conforme preconizado pelo Ministério da Saúde.

Por possibilitar que seus usuários voltem para casa todos os dias, os CAPS evitam a quebra nos laços familiares e sociais, fator muito comum em internações de longa duração ${ }^{18}$.

Os CAPS devem trabalhar articulados com a rede de serviços da região na qual está inserido, pois tem a função de dar suporte e supervisão à rede básica, que é responsável pelos transtornos mentais considerados leves, além de estabelecer parcerias intersetoriais, buscando trabalhar com a área da educação, trabalho, esporte, cultura, lazer, etc., na busca da reinserção dos seus usuários em todas as áreas da vida cotidiana.

Independentemente da modalidade de serviço, os CAPS devem oferecer atendimento individual, em grupos, oficinas terapêuticas executadas por profissional de nível superior ou médio, visitas e atendimentos domiciliares, atendimento à família, atividades comunitárias enfocando a integração na comunidade e inserção familiar e social ${ }^{10}$. 
Ainda com o fim de redefinir o papel do Centro de Atenção Psicossocial de Álcool e outras Drogas 24 h (CAPSAD III), a Portaria № 130 GM/MS, de 26 de janeiro de 2012; aponta que o CAPSAD III é o ponto da RAPS destinado a proporcionar a atenção integral e contínua a pessoas com necessidades relacionadas ao consumo de álcool, crack e outras drogas, com funcionamento nas 24 (vinte e quatro) horas do dia e em todos os dias da semana, inclusive finais de semana e feriados ${ }^{19}$.

Nesses serviços as equipes são multidisciplinares e tem como uma de suas metas promover a reabilitação psicossocial de seus usuários. Ainda nessa perspectiva, a abstinência não pode ser o único objetivo a ser alcançado, deve-se trabalhar com a estratégia da Redução de Danos (RD) ao reconhecer cada usuário em suas singularidades, traçando estratégias mútuas voltadas para a defesa da vida e aumento do grau de liberdade e de corresponsabilidade.

Os desafios impostos pela Reforma Psiquiátrica brasileira e pelo SUS no que diz respeito à superação do antigo modelo de tratamento e a consequente reestruturação da assistência à Saúde Mental, a partir da organização dos serviços substitutivos da rede, traz a necessidade da criação do Projeto Terapêutico Singular (PTS), como uma das estratégias de ações, nos atendimentos direcionados aos usuários do serviço.

A essência do PTS é a discussão das estratégias a serem utilizadas com o usuário durante o seu tratamento. Acreditamos que esse momento é fundamental para que os profissionais entendam os aspectos biológicos, subjetivos e comportamentais da pessoa a ser atendida, além de compreender sua rede social, familiar, cultural, funcional (trabalho) e socioeconômica, de forma a estruturar um PTS voltado para os objetivos, expectativas e demandas do tratamento do usuário.

A proposta do PTS tem a intencionalidade de proporcionar uma atuação integrada da equipe, em que os diferentes saberes dos 
profissionais se entrelacem e possam auxiliar na definição de propostas de ações voltadas para um sujeito individual dentro da coletividade da instituição, trazendo com isso uma eficácia maior no atendimento singular das necessidades de cada usuário.

Nesse sentido, os profissionais de saúde, no estabelecimento do vínculo terapêutico, passam também a ser corresponsáveis pelos caminhos a ser construídos pelo usuário e pelas muitas vidas que a ele se ligam e que nele se expressam ${ }^{20}$.

Segundo os dados do MS (2015), até dezembro de 2014, contamos com aproximadamente 2209 CAPS funcionando no Brasil. Atualmente a cobertura nacional é de 0,86 CAPS/100 mil habitantes, o que aponta uma cobertura muito boa ${ }^{21}$.

Em relação aos dados do Estado de São Paulo ${ }^{21}$ contamos com o total de 353 CAPS, apontando uma cobertura muito boa $(0,77)$. No que se refere aos CAPSad, o estado tem 76 CAPSad II e 14 CAPSad III. Já o município de São Paulo conta com 17 CAPSad II e 09 CAPSad III. É uma rede importante, mas que ainda é insuficiente para atender à demanda cada dia mais crescente. 


\subsection{As Atitudes}

O conceito de atitudes a área da psicologia, comportamento e cognição é apresentado e trabalhado pela literatura internacional há aproximadamente 80 anos ${ }^{22-24}$.

O comportamento humano é frequentemente analisado e justificado por meio de traços de personalidade, tanto pelos estudiosos do comportamento quanto pela população leiga. Um exemplo disso é o fato de que se uma pessoa mente ou trai, ela é considerada desonesta. Se têm um mal desempenho em alguma atividade, diz-se que thes falta motivação para aquilo. De forma semelhante, o conceito de atitude é o foco para explicação de alguns comportamentos humanos e sociais. Avalia-se as atitudes que as pessoas tem com relação à religião, a doenças, fumar, e, com destaque, ao hábito de beber ${ }^{25}$.

Uma vez que as atitudes estão ligadas intrinsecamente a sentimentos e pensamentos, e não podemos ter acesso a isso de uma forma direta, a ciência vêm desenvolvendo, ao longo dos anos, ferramentas que objetivam a mensuração subjetiva das atitudes frente a algum conceito. Pode-se observar um comportamento, ações, linguagem verbal e não verbal, bem como o uso de escalas de avaliação ${ }^{25}$.

"Uma atitude é uma disposição para responder favoravelmente ou desfavoravelmente a um objeto, pessoa, instituição ou acontecimento". Apesar de haver uma variação em como se avaliam as atitudes, as avaliações normalmente são dicotômicas (prazerosadesagradável, positiva-negativa, a favor-contra, e outros). As estratégias de avaliação de atitudes por meio de escalas, por exemplo, tendem a avaliar o indivíduo dentro de um espectro (normalmente por meio de um escore) dentro da atitude que se propõe a medir ${ }^{25}$. 
Dentro deste conceito seria possível medir, por exemplo, se um indivíduo ou um grupo possuem atitudes, de forma geral, a favor ou contra a legalização do aborto, a liberdade de religião, descriminalização das drogas, etc. As atitudes normalmente são afetadas pelo subjetivo do indivíduo: a sua formação, as suas crenças, o seu contexto cultural, entre outros ${ }^{25}$.

Os descritores em Ciências da Saúde da Biblioteca Virtual em Saúde definem atitude como "Predisposição adquirida e duradoura que age sempre do mesmo modo diante de uma determinada classe de objetos" 26 . Desta forma, atitude é uma inclinação que o indivíduo possui para praticar seus atos, ou planejar ações, de acordo com concepções anteriores, formadas pela complexidade de sua personalidade e comportamento.

Avaliar as atitudes de profissionais da saúde tem sido tópico frequente de pesquisas ${ }^{27-31}$. Com o objetivo final de tentar prever melhores práticas de cuidado ao ser humano, a avaliação das atitudes em pesquisas se justifica como uma forma de buscar recursos educativos, formativos, quebra de estigma e outras importantes estratégias de enfrentamento para que o cuidado seja cada vez mais humanizado ${ }^{27-31}$.

Desta forma, justifica-se a avaliação de atitudes dos profissionais, visando melhores práticas de cuidado em saúde. 


\subsection{Atitudes frente ao Álcool, Alcoolismo e o Alcoolista}

O tema atitudes e conhecimentos dos profissionais da saúde diante do álcool e outras drogas tem despertado pouco interesse dos pesquisadores, no Brasil essa temática começou a ser explorada a partir da segunda metade da década de 1990, o que causou uma lacuna nessa área do conhecimento ${ }^{32}$.

Os mesmos autores realizaram uma revisão da literatura dos últimos 50 anos acerca da temática: atitudes e conhecimentos de profissionais de saúde diante do álcool, alcoolismo e do alcoolista, e identificaram apenas 16 publicações. Os autores observaram que a maior concentração $(37,5 \%)$ de publicações se deu no período de 2000 a $2009^{32}$.

O grupo que tem despertado maior interesse dos pesquisadores, neste tema, foram os enfermeiros. A origem dessas publicações, segundo a amostra analisada pelos autores, é predominantemente da Inglaterra $(56,25 \%)$, seguida dos EUA $(18,75 \%)^{32}$.

Os autores também realizaram uma análise qualitativa das publicações e categorizaram as publicações em três temáticas: a $1^{\circ}$ se refere a pesquisas que examinam as atitudes de profissionais de saúde e foi composta por seis publicações. A $2^{\circ}$ temática diz respeito aos estudos relacionados ao conhecimento de profissionais de saúde diante do álcool, do alcoolismo e do alcoolista e foi composta por quatro artigos. Já os estudos que abordaram especificamente a relação entre atitudes e conhecimentos de profissionais da saúde dos diversos espaços de atuação diante de questões relacionadas ao uso de bebidas alcoólicas, ao beber social, ao alcoolista, tratamentos e à etiologia do alcoolismo, considerada a $3^{\circ}$ temática, foi composta por seis artigos ${ }^{32}$. 
Além desses estudos, outra pesquisa avaliou as atitudes de 82 enfermeiros de um hospital geral em relação ao uso abusivo de SPAS, na Escócia, seus resultados sugerem que os profissionais têm atitudes de julgamento e punitivas aos toxicodependentes ${ }^{33}$.

Estudo realizado com profissionais de saúde que trabalhavam com usuários de drogas injetáveis (DI) indicaram que os trabalhadores que acreditavam que o uso de drogas estava dentro do controle do usuário, exibiram mais atitudes negativas em relação aos seus clientes ${ }^{27}$.

Estudo de 2003 ressaltou que as atitudes de enfermeiros frente ao abuso de SPAS em doentes mentais são geralmente abaixo do ideal e trazem impacto negativo sobre a qualidade da assistência de enfermagem prestada ${ }^{34}$.

As atitudes dos enfermeiros, de um serviço de emergência em Hong Kong, para com os pacientes alcoolistas tenderam a ser negativas ${ }^{35}$.

Em Londres, foram pesquisados 63 enfermeiros psiquiátricos forenses, os autores concluíram que as atitudes desses enfermeiros para com o abuso de substâncias em clientes forenses, são melhores do que outros grupos de agentes comunitários de saúde mental ${ }^{34}$.

Pesquisa sobre as atitudes dos enfermeiros de um hospital geral na Austrália indicou que em média apresentaram atitudes neutras ou positivas para problemas de alcoolismo. Também demonstrou que os enfermeiros que se situavam em maior faixa etária concordavam que o alcoolismo é uma doença e eram menos pessimistas frente ao alcoolista ${ }^{36}$

$\mathrm{Na}$ literatura nacional, a maioria dos enfermeiros não se sentiam satisfeitos em trabalhar com pacientes alcoolistas, os autores sugerem que a insatisfação decorre das questões referentes ao conhecimento e, consequentemente, do despreparo profissional para a abordagem do problema ${ }^{37}$. 
Sobre as atitudes de enfermeiros de hospital geral no que se refere ao álcool e ao beber e encontraram que esses consideram que: as bebidas alcoólicas são prejudiciais $(54,4 \%)$, beber com moderação não é inofensivo $(57,1 \%)$ e é errado $(47,4 \%)$. Ainda revelaram a dificuldade desses profissionais na aceitação do beber como um direito da pessoa ${ }^{38}$.

Outro estudo que objetivou conhecer as concepções e as tendências de atitudes de enfermeiros, de Unidades de Atenção Básica de Saúde frente ao álcool, ao alcoolismo e ao alcoolista, encontrou que os profissionais são permissivos ao uso moderado do álcool, entretanto rejeitam o alcoolismo, concebendo-o como uma doença que pode ser fatal e tendem a associá-lo à vontade da pessoa, revelando a influência do conceito moral em suas concepções e atitudes ${ }^{39}$.

Em pesquisa realizada com enfermeiros de um hospital universitário do Estado de São Paulo, encontrou-se tendência a atitudes positivas, fato demonstrado quando os enfermeiros sentemse capazes para ajudar pacientes alcoolistas a alcançarem a recuperação. No entanto, identificou conflito nas atitudes frente à vontade e ao querer do alcoolista, revelando influência do modelo moral de explicação para o alcoolismo ${ }^{40}$.

O mesmo autor também realizou pesquisas com estudantes de enfermagem. No estudo foram avaliadas as atitudes de uma amostra de estudantes de enfermagem frente ao álcool, alcoolismo e alcoolista, de duas escolas do setor privado, de uma cidade do interior de São Paulo. Os resultados demonstraram que as atitudes frente ao alcoolista foram negativas. A maioria dos participantes considerou 0 alcoolista culpado por seus problemas de saúde e preferiu não trabalhar com esse tipo de paciente ${ }^{41,42}$.

De modo geral, os estudos sobre as atitudes de profissionais de saúde frente o uso de SPAS, permitem evidenciar que os profissionais tendem a apresentar atitudes negativas quando em 
contato com o paciente alcoolista, independente do contexto de atenção.

Outro fato preocupante é o dos estudantes de enfermagem apresentar tendência a atitudes negativas, antes mesmo de trabalharem com a população usuária de SPAS, que atualmente tem elevado a demanda por atendimento nos serviços de saúde públicos, principalmente nas urgências e emergência.

Frente às constatações dos dados epidemiológicos e da necessidade de profissionais capacitados para atender à demanda gerada pelo uso abusivo de álcool e outras drogas, acreditamos que investigar a atitude dos profissionais que trabalham no CAPSad, principal equipamento de saúde territorial especializado na área de $A O D$, pode contribuir para a reflexão dos profissionais envolvidos no atendimento, uma vez que as atitudes e conhecimentos influenciam diretamente na qualidade da atenção prestada pelos profissionais de saúde.

Para realizar essa investigação, os autores elegeram a escala de atitudes frente ao álcool, alcoolismo e alcoolista - EAFAAA, que objetiva identificar traços positivos e negativos dessas atitudes por parte de profissionais da saúde.

A EAFAAA possui bons índices de confiabilidade e consistência interna, podendo ser utilizada em estudos brasileiros para avaliação das atitudes dos profissionais de saúde frente ao álcool, alcoolismo e alcoolista ${ }^{43}$.

Diversos estudos de validação dessa escala foram realizados no idioma português e recentemente em espanhol. A referida escala é citada com frequência na literatura e utilizada em diversos estudos na área de saúde mental e adições ${ }^{37-39,43-48 .}$

A versão da EAFAAA utilizada no presente estudo possui 50 itens, que avaliam as atitudes dos profissionais em uma escala de likert de 1 a 5. Pontuações finais no escore da escala mais elevadas 
predizem profissionais com atitudes mais positivas frente ao álcool, alcoolismo e alcoolista. Alguns itens possuem lógica invertida, e precisam ter os seus valores considerados com valores opostos para o cálculo das atitudes de forma adequada. 


\section{OBJETIVOS}

\subsection{OBJETIVO GERAL}

Avaliar em uma amostra de 12 CAPSad da cidade de São Paulo, pertencentes ao projeto "Avaliação de CAPSad dos Estados de São Paulo, Minas Gerais e Amapá" ${ }^{1}$ as atitudes dos profissionais desses serviços frente ao álcool, alcoolismo e alcoolista.

\subsection{OBJETIVOS ESPECÍFICOS}

1) Realizar análise descritiva das variáveis sócio econômicas (caracterização) dos profissionais dos CAPSad onde os dados foram coletados;

2) Mensurar as atitudes dos profissionais dos CAPSad, por meio da Escala de Atitudes Frente ao Álcool, ao Alcoolismo e ao Alcoolista (EAFAAA) (VARGAS, 2011).

3) Verificar se existe associação entre as atitudes dos profissionais frente ao álcool, ao alcoolismo e ao alcoolista, mensurada por meio da EAFAAA (variável dependente), e variáveis sociodemográficas e relacionadas ao trabalho no CAPSad dos trabalhadores (variáveis independentes), buscando fatores associados a melhores atitudes por parte dos profissionais.

\footnotetext{
${ }^{1}$ Projeto de Pesquisa em andamento. Oliveira MAF et al. "Avaliação dos Centros de Atenção Psicossocial álcool e outras Drogas nos Estados de São Paulo, Minas Gerais e Amapá". Escola de Enfermagem da USP, Grupo de Estudos em Álcool e outras Drogas - GEAD. 2010 - 2016.
} 


\section{MÉTODOS}

Trata-se de uma pesquisa que utiliza métodos quantitativos transversais, descritivos e exploratórios.

\subsection{PROCEDIMENTOS ÉTICOS}

O projeto de Avaliação dos CAPSad do Estado de São Paulo foi submetido e aprovado pelo CEP - EEUSP, com o ํo. 1.001/2011(Anexo I) e registrado na Secretaria Municipal de Saúde de São Paulo, com o parecer CAEE de número 0145.0.196.162-11 (Anexo II).

Em seguida, os coordenadores, membros das equipes técnicas, usuários e familiares dos CAPSad foram informados sobre a realização da pesquisa, sendo-Ihes entregue uma carta explicativa.

Após a obtenção do Termo de Consentimento Livre e Esclarecido (TCLE) dos participantes (Apêndices I e II), se deu início à coleta de dados.

\subsection{PERÍODO DE REALIZAÇÃO DO ESTUdO E LOCAIS ONDE FOI REALIZADO}

O estudo foi desenvolvido na EEUSP entre os anos de 2010 e 2014, sendo que as coletas de dados foram realizadas em 12 CAPSad da cidade de São Paulo, credenciados ao Ministério da Saúde, com no mínimo um ano de funcionamento. Como parte de um projeto maior do GEADEEUSP, a presente tese é uma avaliação preliminar dos CAPSad da cidade de São Paulo. Foram incluídos no presente estudo os CAPSad em que as coletas foram realizadas entre o mês de maio de 2013 e o mês de Abril de 2014, que compreendem: CAPSad II 
Cachoeirinha, CAPSad III Centro, CAPSad II Ermelino Matarazzo, CAPSad II Ipiranga/Arapuá, CAPSad II Jabaquara, CAPSad II Pinheiros, CAPSad II Pirituba, CAPSad II Sacomã, CAPSad III Santana, CAPSad II Santo Amaro, CAPSad III São Miguel, CAPSad II Vila Mariana.

\subsection{AMOSTRA}

Participaram do estudo todos os trabalhadores dos 12 CAPSad supramencionados.

De um total de 349 trabalhadores cadastrados, 288 foram localizados e entrevistados (perda de 17,4\%). Dois trabalhadores foram excluídos do banco de dados pois a entrevista não foi devidamente finalizada (os coletadores não preencheram completamente o instrumento de coleta de dados).

Os motivos para perdas de sujeitos (61 perdas) trabalhadores incluem: trabalhadores em licença, férias ou afastados durante 0 período de coleta de dados, recusaram-se a participar da pesquisa e trabalhadores alocados em outros serviços.

Figura 1: Fluxograma da participação dos sujeitos de pesquisa

\section{Profissionais}

\section{Total cadastrados: 349}

\section{Entrevistados: 288}

\section{Excluídos: 02}

\section{Perdas: 61}




\subsection{CRITÉRIOS PARA INCLUSÃO E EXCLUSÃO DE PARTICIPANTES}

Para participarem do estudo, os profissionais deveriam ter no mínimo um ano (12 meses) de trabalho no serviço. Foram excluídos aqueles que estivessem afastados por licença-médica, maternidade, prêmio e outros no período da coleta de dados (contabilizados como perdas acima).

Para estabelecer este período de um ano de trabalho no serviço, os autores levaram em consideração a justificativa dada por um estudo avaliativo realizado no CAPS dos Estados da Região Sul entre os anos de 2006 e 200949.

\subsection{COLETA DE DADOS}

Após a assinatura do TCLE do Secretário da Saúde/Coordenador de saúde mental, os pesquisadores entraram em contato com as coordenações dos CAPSad. E com a anuência dos coordenadores $e$ as respectivas assinaturas do TCLE, foram agendadas as visitas em dias e horários convenientes ao funcionamento dos serviços. 


\subsection{INSTRUMENTOS DE COLETA DE DADOS}

Para o presente estudo foi utilizado um questionário de dados sócio demográficos, a Escalas de Satisfação SATIS-BR ${ }^{50-52}$ e a Escala de Atitudes frente ao álcool, alcoolismo e alcoolista - EAFAAA 53.

As Escalas de Satisfação SATIS-BR ${ }^{50-52}$ integram um conjunto de três escalas para avaliação de Serviços de Saúde Mental (Escalas de Avaliação da Satisfação dos usuários e familiares com os Serviços de Saúde Mental - SATIS-BR 52, 54 e a Escala de Avaliação da Satisfação de Profissionais em Serviços de Saúde Mental - SATIS$\mathrm{BR}^{50}$.

De acordo com a descrição de escore do instrumento validado, quanto mais próxima de 5 a média das respostas dos participantes (usuários, familiares e profissionais), melhor a satisfação com o serviço ${ }^{55}$.

Essas escalas foram elaboradas pela Divisão de Saúde Mental da Organização Mundial de Saúde (OMS) e, posteriormente, foram validadas para o Brasil por Bandeira e colaboradores entre 2000 e 2002 e atualizadas em 2012.

A Escala de Atitudes frente ao álcool, alcoolismo e alcoolista EAFAAA foi construída em sua primeira versão no ano de $2005{ }^{56}$. Esta escala foi construída com o objetivo de avaliar os principais grupos de atitudes dos profissionais de saúde frente ao álcool, ao alcoolismo e ao alcoolista (fator moral, fator doença, fator etiológico, fator profissional e fator humano) ${ }^{57}$. Diversos estudos de validação da escala mostraram valores elevados de consistência interna e validade, permitindo afirmar que 0 instrumento apresenta bons parâmetros psicométricos ${ }^{53}$. 


\subsection{ESTUDO PILOTO}

Como mencionado acima, os dados do presente estudo fazem parte de uma pesquisa matricial de avaliação dos CAPSad em três estados brasileiros. Antes de realizada a presente pesquisa, com uma amostra de: 12 CAPSad na cidade de São Paulo, 02 CAPSad no interior de São Paulo, 13 CAPSad no estado de Minas Gerais, e 02 CAPSad no Estado do Amapá, foi realizado um estudo piloto no CAPSad da Vila Madalena, em São Paulo, para teste do protocolo de pesquisa e eventuais modificações para o estudo principal.

O estudo piloto foi realizado com os quatro segmentos: coordenador, trabalhadores, usuários e familiares, incluindo a avaliação de prontuários, aplicando-se todos os instrumentos, que resultaram em um relatório para apresentação e discussão das dificuldades encontradas.

Embora este estudo tenha optado por utilizar os instrumentos propostos pelo AVALIA CAPS da região Sul do Brasil ${ }^{49}$, estes não apresentavam especificidade para serem aplicados nos CAPSad, uma vez que naquele estudo, os CAPS avaliados foram do tipo I e II, especializados em saúde mental.

Após o estudo piloto, os instrumentos foram adaptados pelos pesquisadores, de modo $a$ atender às necessidades e contrastes dos CAPSad. O estudo piloto também foi útil para realizar um treino referente à coleta de dados para os pesquisadores envolvidos na investigação.

O CAPSad da Vila Madalena, onde foi desenvolvido o estudo piloto, foi desconsiderado para a coleta de dados da pesquisa, uma vez que a população utilizada no pré-teste não deve ser incluída na investigação, para evitar interferência nos resultados ${ }^{58}$.

Durante o estudo piloto, percebeu-se a dificuldade em utilizar formulários de papel para a coleta e, posteriormente, confeccionar de 
forma manual os bancos de dados. Frente a isto, decidiu-se pelo uso de formulários eletrônicos. Para tanto, utilizamos da plataforma Google Drive, que possui formulários eletrônicos que importam as informações coletadas para um banco de dados em forma de planilhas ${ }^{2}$.

2 Uma cópia em formato PDF pode ser visualizada no endereço eletrônico: http://goo.gl/N21dmj 


\subsection{TRATAMENTO E ANÁLISE DOS DADOS}

Os bancos de dados para os trabalhadores, usuários e familiares exportados do Google Drive foram analisados utilizando-se o Programa IBM SPSS Statistics 20 para Windows $\AA$.

Foi realizada uma análise descritiva dos dados, testes de médias e cálculos dos intervalos de confiança para cada uma das variáveis quantitativas.

Para verificar as associações entre as variáveis, foram realizados modelos de regressão de mínimos quadrados ordinários (Ordinary Least Squares - OLS) univariadas e múltiplas.

O objetivo de uma regressão OLS é traçar uma linha que tem como objetivo prever uma variável de resposta (variável dependente) a partir de uma ou mais variáveis explicativas (variáveis independentes) que minimize a soma do quadrado dos erros ${ }^{59}$.

Uma das condições necessárias para uma análise de regressão OLS é a existência de uma relação linear representada por $y_{i}=\alpha+\beta \boldsymbol{x}_{i}+e_{i}$, que mostra como uma resposta média (variável dependente $y_{i}$ ) varia de acordo com um vetor de variáveis independentes $\boldsymbol{x}_{\boldsymbol{i}}$ com um intercepto $\alpha$, uma inclinação (slope) $\beta$ e um termo de erro $e_{i}{ }^{59}$.

No presente estudo definimos como variável dependente o escore de Atitudes Frente ao Álcool, Alcoolismo e Alcoolista, medida pelo escore da EAFAAA (varia de forma contínua de 1 a 5 ).

As variáveis independentes usadas nos modelos univariados e múltiplos são descritas à medida que apresentamos os modelos nos resultados, uma vez que o número de variáveis é extenso, para facilitar o entendimento de cada um dos modelos.

Como pressuposto básico para o uso da OLS, temos a distribuição aproximadamente normal da variável dependente ${ }^{59}$. Esse pressuposto foi verificado por meio da proximidade das médias e 
medianas para as variáveis, bem como por meio de gráfico de estimativa de densidade de kernel. A variável dependente permitiu assumir uma distribuição aproximadamente normal.

Na primeira etapa das análises inferenciais, fizemos a análise univariada de cada variável e incluímos no modelo múltiplo de cada classe as variáveis cujo valor de $p \leq 0,3$. Em seguida, essas variáveis foram incluídas em um modelo múltiplo final, e considerou-se estatisticamente significante as variáveis com valor de $p \leq 0,05$. Os erros-padrão são robustos à heterocedasticidade de acordo com o método proposto por White ${ }^{60}$.

As seguintes variáveis foram incluídas nos modelos:

Gênero foi mensurado em 0- masculino e 1-feminino;

Cor/raça por meio da auto-declaração do trabalhador, dividimos em duas categorias: 0- branco e 1- não branco.

Idade foi mensurada em número de anos.

Tempo de trabalho no CAPSad nas seguintes categorias: 0 - 1 ano, 1 - 2 a 4 anos, 2 - de 5 a 7 anos, 3 - de 8 a 10 anos, 4 - mais de 10 anos.

Renda total: 0 - 1 a 3 salários mínimos; 1 - 4 a 7 salários mínimos; 2 - 8 a 11 salários mínimos e 3 - acima de 12 salários mínimos;

Profissão: 0 - técnico administrativo; 1 - técnico da área de saúde (técnico de enfermagem ou farmácia); 2 - oficineiro; 3 - nível superior de saúde.

Estado civil: 0 - sem companheiro e 1 - com companheiro;

Pós Graduação - se o profissional fez pós graduação 0 - Não ou 1 - Sim.

Mudança nas condições de Trabalho desde que tem vínculo com o CAPSad: 0 - pioraram; 1 - não mudaram; 2 - melhoraram pouco; e 3 - melhoraram muito. 
Incômodos: corresponde ao somatório das respostas de quatro perguntas a respeito de situações incomodas que os trabalhadores enfrentam no campo de trabalho, variando de 0 a 4 .

Possibilidades de trabalho: índice construído a partir de somatório de respostas a oito itens referentes à autonomia do trabalhador no desenvolvimento de atividades profissionais cotidianas, variando de 0 a 8 .

Modalidade de tratamento: a modalidade de tratamento que o trabalhador considera que é utilizada no CAPSad, sendo 0 - Redução de Danos, 1 - Abstinência total, 2 - As duas modalidades, 3 - Não sei.

Satisfação Global com o serviço - escore de satisfação calculado por meio da escala SATIS. Variável numérica contínua, de 1 a 5 .

Inclusão no tratamento, medida em 0 - Não e 1 - Sim para os seguintes critérios: O consumo de álcool e outras drogas; a gravidade do consumo de álcool e outras drogas; O impacto global na vida do uso de álcool e outras drogas. 


\section{RESULTADOS}

\subsection{ANÁLISE DESCRITIVA - PERFIL DOS SUJEITOS DE PESQUISA}

$\mathrm{Na}$ tabela 1 apresentamos o número de trabalhadores, em cada CAPSad.

Tabela 1: Natureza dos Sujeitos da pesquisa por CAPSad. São Paulo/SP ( $\mathrm{n}=\mathbf{2 8 8})$

\begin{tabular}{l|cc}
\hline \multicolumn{1}{c}{ CAPSad } & \multicolumn{2}{c}{ Trabalhadores } \\
\hline & $\mathrm{N}$ & $\%$ \\
Cachoeirinha & 16 & $5,6 \%$ \\
Centro & 51 & $17,7 \%$ \\
Ermelino & 20 & $6,9 \%$ \\
Ipiranga & 22 & $7,6 \%$ \\
Jabaquara & 8 & $2,8 \%$ \\
Pinheiros & 16 & $5,6 \%$ \\
Pirituba & 13 & $4,5 \%$ \\
Sacomã & 24 & $8,3 \%$ \\
Santana & 40 & $13,9 \%$ \\
Santo Amaro & 16 & $5,6 \%$ \\
São Miguel & 49 & $17,0 \%$ \\
Vila Mariana & 13 & $4,5 \%$ \\
Total & 288 & $100,0 \%$ \\
\hline
\end{tabular}

Fonte: CAPSad, São Paulo-SP, 2014.

Para garantir o atendimento ao pressuposto de normalidade das variáveis dependentes, realizamos a estimativa de Densidade de kernel. Os gráficos obtidos foram ilustrados com uma curva normal para mostrar a aproximação da normalidade dos dados, e estão apresentados nas figuras 3 a 8 , como se segue: 
Figura 2: Estimativa de densidade de kernel para atitudes trabalhadores

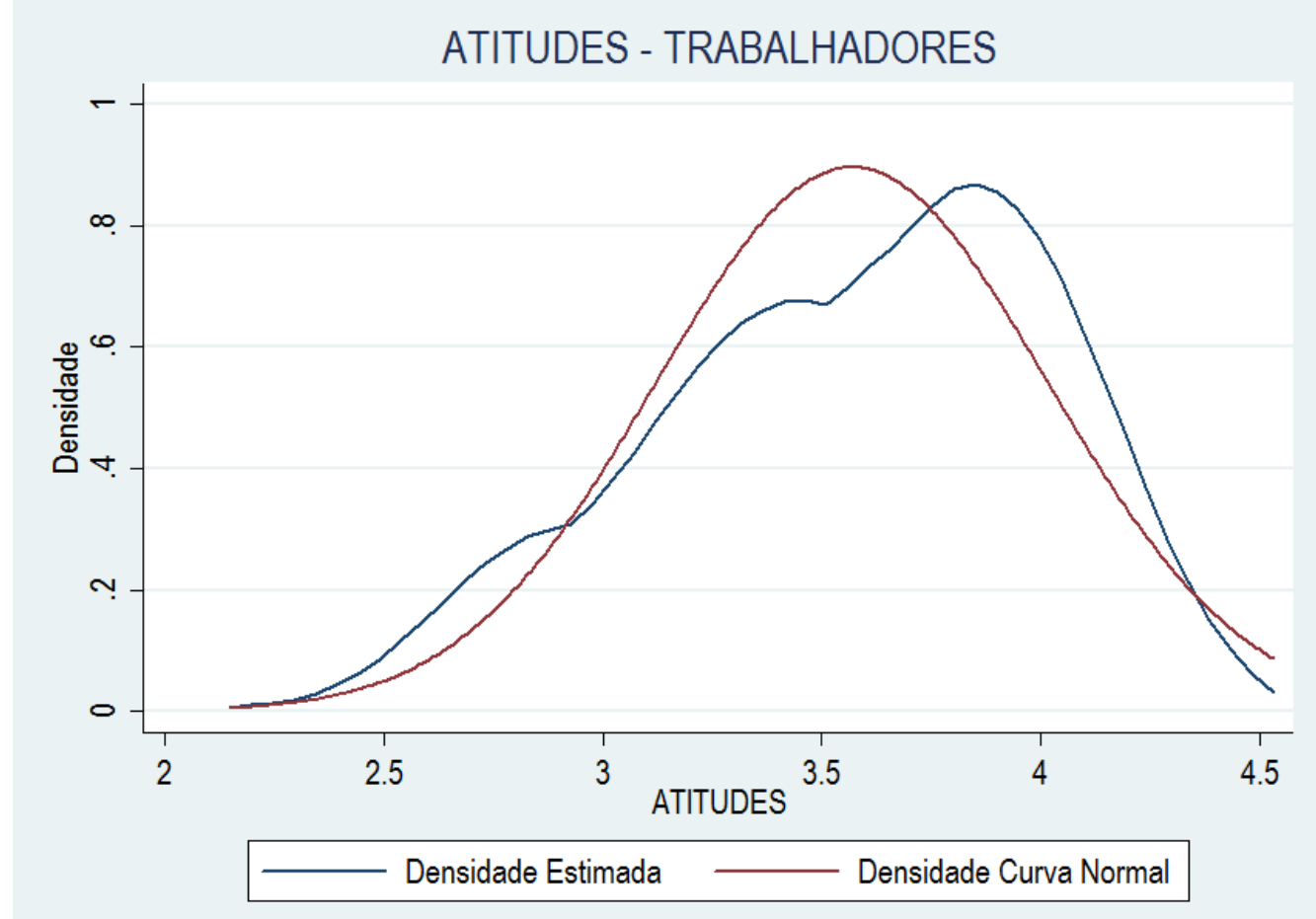

Como observado nas figuras acima, as variáveis dependentes respeitam o pressuposto da normalidade, o que permite o uso da regressão OLS. 


\subsubsection{Caracterização dos Profissionais dos CAPSad de São Paulo/SP}

Os resultados descritos a seguir referem-se aos dados sociodemográficos dos trabalhadores que compõem as equipes dos CAPSad. Há um predomínio de profissionais do sexo feminino, de cor branca, casada ou com companheiro, a idade média foi de 40 anos.

Em relação à escolaridade, a maioria dos profissionais $(35,4 \%)$ possui pós-graduação, seguido daqueles $(17,7 \%)$ com ensino superior completo.

Os dados referentes às funções exercidas pelos profissionais nos CAPSad, do município de São Paulo-SP, estão assim distribuídos: $20,8 \%$ da amostra exercem atividades de nível médio e fundamental de enfermagem, técnico e auxiliar de enfermagem, 12,8 $\%$ desempenham atividades administrativas, $11,5 \%$ são psicólogos; $8 \%$ são médicos; $7,6 \%$ são enfermeiros; $7,3 \%$ são assistentes sociais, com a mesma porcentagem, os terapeutas ocupacionais, seguido pelos oficineiros $5,9 \%$ e técnicos de farmácia $(4,2 \%)$. As funções com menor porcentagem nos CAPSad analisados, do município de SP, são: educador físico $(3,1 \%)$, farmacêutico $(3,5 \%)$ e fonoaudiólogo $(0,3 \%)$.

Observa-se que $43,4 \%$ dos profissionais trabalham em CAPSad entre 2 a 4 anos, sendo que 47,9\% desses profissionais trabalha no serviço onde os dados foram coletados entre 2 a 4 anos.

A maioria dos trabalhadores $(71,9 \%)$ não possui outro vínculo empregatício e recebem de 4 a 7 salários mínimos $(39,2 \%)$, de 1 a 3 salários mínimos (22,9\%), de 8 a 11 salários mínimos (13,2\%) e acima de 16 salários mínimos há apenas $12,8 \%$ dos profissionais. 
Tabela 2: Apresentação das informações sociodemográficas segundo os profissionais de saúde dos CAPSad, São Paulo-SP $(\mathrm{n}=\mathbf{2 8 8})$

\begin{tabular}{|c|c|c|c|}
\hline \multicolumn{2}{|c|}{ Variáveis } & Média & Mediana \\
\hline \multicolumn{2}{|l|}{ Idade } & 40 & 38 \\
\hline \multicolumn{2}{|l|}{ Carga horária } & 35 & 40 \\
\hline \multicolumn{2}{|c|}{ Variáveis } & $\mathbf{n}$ & $\%$ \\
\hline \multirow{3}{*}{ Sexo } & Masculino & 88 & $30.6 \%$ \\
\hline & Feminino & 200 & $69.4 \%$ \\
\hline & Total & 288 & $100 \%$ \\
\hline \multirow{5}{*}{ Etnia } & Branca & 165 & $57.3 \%$ \\
\hline & Negra & 38 & $13.2 \%$ \\
\hline & Mulata/Parda & 83 & $28.8 \%$ \\
\hline & Amarelo & 2 & $0.7 \%$ \\
\hline & Total & 288 & $100 \%$ \\
\hline \multirow{5}{*}{ Estado Civil } & Solteiro & 109 & $37.8 \%$ \\
\hline & $\begin{array}{l}\text { Casado/Com } \\
\text { companheiro }\end{array}$ & 138 & $47.9 \%$ \\
\hline & $\begin{array}{l}\text { Separado/Divorci } \\
\text { ado }\end{array}$ & 35 & $12.2 \%$ \\
\hline & Viúvo & 6 & $2.1 \%$ \\
\hline & Total & 288 & $100 \%$ \\
\hline \multirow{11}{*}{ Escolaridade } & \multirow{2}{*}{$\begin{array}{l}\text { Ensino } \\
\text { Fundamental } \\
\text { Completo }\end{array}$} & 5 & $1.7 \%$ \\
\hline & & & \\
\hline & $\begin{array}{l}\text { Ensino Médio } \\
\text { Completo }\end{array}$ & 26 & $9.0 \%$ \\
\hline & Ensino Médio & 7 & $2.4 \%$ \\
\hline & $\begin{array}{l}\text { Curso lecnico } \\
\text { completo }\end{array}$ & 33 & $11.5 \%$ \\
\hline & $\begin{array}{l}\text { Ensino Superior } \\
\text { Completo }\end{array}$ & 51 & $17.7 \%$ \\
\hline & $\begin{array}{l}\text { Ensino Superior } \\
\text { Incompleto }\end{array}$ & 53 & $18.4 \%$ \\
\hline & \multirow{2}{*}{$\begin{array}{l}\text { Pós Graduação } \\
\text { Completa }\end{array}$} & 102 & $35.4 \%$ \\
\hline & & & \\
\hline & $\begin{array}{l}\text { Pós Graduação } \\
\text { Incompleta }\end{array}$ & 11 & $3.8 \%$ \\
\hline & Total & 288 & $100 \%$ \\
\hline
\end{tabular}




\begin{tabular}{|c|c|c|c|}
\hline \multirow{6}{*}{$\begin{array}{l}\text { Tempo de } \\
\text { trabalho em } \\
\text { CAPSad }\end{array}$} & 1 ano & 76 & $26.4 \%$ \\
\hline & Entre 2 a 4 anos & 125 & $43.4 \%$ \\
\hline & Entre 5 a 7 anos & 32 & $11.1 \%$ \\
\hline & Entre 8 a 10 anos & 18 & $6.2 \%$ \\
\hline & Mais que 10 anos & 37 & $12.8 \%$ \\
\hline & Total & 288 & $100 \%$ \\
\hline \multirow{6}{*}{$\begin{array}{l}\text { Tempo de } \\
\text { trabalho nesse } \\
\text { CAPSad }\end{array}$} & 1 ano & 92 & $31.9 \%$ \\
\hline & Entre 2 a 4 anos & 138 & $47.9 \%$ \\
\hline & Entre 5 a 7 anos & 16 & $5.6 \%$ \\
\hline & Entre 8 a 10 anos & 13 & $4.5 \%$ \\
\hline & Mais que 10 anos & 29 & $10.1 \%$ \\
\hline & Total & 288 & $100 \%$ \\
\hline \multirow{3}{*}{$\begin{array}{l}\text { Outro vínculo } \\
\text { trabalhista }\end{array}$} & Não & 207 & $71.9 \%$ \\
\hline & Sim & 81 & $28.1 \%$ \\
\hline & Total & 288 & $100 \%$ \\
\hline \multirow{6}{*}{$\begin{array}{l}\text { Renda mensal } \\
\text { bruta do total de } \\
\text { vínculos } \\
\text { empregatícios }\end{array}$} & $\begin{array}{l}1 \text { a } 3 \text { Salários } \\
\text { Mínimos }\end{array}$ & 84 & $22.9 \%$ \\
\hline & $\begin{array}{l}4 \text { a } 7 \text { Salários } \\
\text { Mínimos }\end{array}$ & 129 & $39.2 \%$ \\
\hline & $\begin{array}{l}8 \text { a } 11 \text { Salários } \\
\text { Mínimos }\end{array}$ & 39 & $13.2 \%$ \\
\hline & $\begin{array}{l}12 \text { a } 15 \text { Salários } \\
\text { Mínimos }\end{array}$ & 22 & $7.3 \%$ \\
\hline & Acima de 16 & 14 & $4.5 \%$ \\
\hline & Total & 288 & $100 \%$ \\
\hline \multirow{14}{*}{ Profissão } & Administrativo & 37 & $12.8 \%$ \\
\hline & Assistente Social & 21 & $7.3 \%$ \\
\hline & Educador físico & 9 & $3.1 \%$ \\
\hline & Enfermeiro & 22 & $7.6 \%$ \\
\hline & Farmacêutico & 10 & $3.5 \%$ \\
\hline & Fonoaudiólogo & 1 & $0.3 \%$ \\
\hline & Manutenção & 22 & $7.6 \%$ \\
\hline & Médico & 23 & $8.0 \%$ \\
\hline & Oficineiro & 17 & $5.9 \%$ \\
\hline & Psicólogo & 33 & $11.5 \%$ \\
\hline & $\begin{array}{l}\text { Técnico de } \\
\text { Farmácia }\end{array}$ & 12 & $4.2 \%$ \\
\hline & $\begin{array}{l}\text { Técnico/auxiliar } \\
\text { de enfermagem }\end{array}$ & 60 & $20.8 \%$ \\
\hline & $\begin{array}{l}\text { Terapeuta } \\
\text { Ocupacional }\end{array}$ & 21 & $7.3 \%$ \\
\hline & Total & 288 & $100.0 \%$ \\
\hline
\end{tabular}

Fonte: CAPSad, São Paulo-SP, 2014. 


\subsubsection{Caracterização das Atitudes dos Profissionais dos CAPSad de São Paulo}

A tabela 3 apresenta os escores obtidos na Escala de Atitudes Frente ao Álcool, Alcoolismo e Alcoolista (EAFAAA) como um todo e em cada um dos fatores da escala pelos profissionais dos CAPSad que responderam à pesquisa $(n=288)$.

A média do escore obtido na EAFAAA foi de 3,56 , com tendência dos profissionais apresentarem atitudes positivas frente ao álcool, alcoolista e alcoolismo. Ao verificar por fator, nota-se que a média para o fator 1, 2 e 3 apresenta tendência sugestiva de atitudes positivas quando comparadas com a média observada. Já para o fator 4 a tendência apresentada é sugestiva de atitudes negativas se comparadas com a média observada. 
Tabela 3: Escores obtidos na EAFAAA, global e em seus fatores $(n=229)$.

\begin{tabular}{|c|c|c|c|c|}
\hline \multicolumn{3}{|l|}{ EAFAAA } & \multicolumn{2}{|c|}{$\begin{array}{l}\text { Erro } \\
\text { Padrão }\end{array}$} \\
\hline \multirow{5}{*}{$\begin{array}{l}\text { Fator } 1.0 \text { trabalhar } \\
\text { e o relacionar-se } \\
\text { com o alcoolista }\end{array}$} & \multicolumn{2}{|l|}{ Média } & 3,84 & 0,03 \\
\hline & \multirow[b]{2}{*}{ IC 95\% } & $\begin{array}{l}\text { Limite } \\
\text { Inferior }\end{array}$ & 3,78 & \\
\hline & & $\begin{array}{l}\text { Limite } \\
\text { Superior }\end{array}$ & 3,90 & \\
\hline & \multicolumn{2}{|l|}{ Mediana } & 3,90 & \\
\hline & \multicolumn{2}{|l|}{ Desvio Padrão } & ,521 & \\
\hline \multirow{6}{*}{$\begin{array}{l}\text { Fator } 2 \text {. Atitudes } \\
\text { frente ao alcoolista }\end{array}$} & Média & & 3,97 & 0,05 \\
\hline & \multirow[b]{2}{*}{ IC 95\% } & Limite & 3,88 & \\
\hline & & $\begin{array}{l}\text { Inerlor } \\
\text { Limite } \\
\text { Superior }\end{array}$ & 4,06 & \\
\hline & \multicolumn{2}{|l|}{ Mediana } & 4,10 & \\
\hline & \multicolumn{2}{|l|}{ Desvio Padrão } & 0,76 & \\
\hline & Média & & 2,97 & 0,03 \\
\hline \multirow{4}{*}{$\begin{array}{l}\text { Fator 3. Atitudes } \\
\text { frente ao } \\
\text { alcoolismo } \\
\text { (etiologia) }\end{array}$} & \multirow{2}{*}{ IC $95 \%$} & $\begin{array}{l}\text { Limite } \\
\text { Inferior }\end{array}$ & 2,92 & \\
\hline & & $\begin{array}{l}\text { Limite } \\
\text { Superior }\end{array}$ & 3,02 & \\
\hline & \multicolumn{2}{|l|}{ Mediana } & 3,00 & \\
\hline & \multicolumn{2}{|l|}{ Desvio Padrão } & 0,44 & \\
\hline \multirow{6}{*}{$\begin{array}{l}\text { Fator 4. Atitudes } \\
\text { frente ao uso do } \\
\text { álcool }\end{array}$} & \multicolumn{2}{|l|}{ Média } & 3,26 & 0,05 \\
\hline & \multirow[b]{2}{*}{ IC 95\% } & $\begin{array}{l}\text { Limite } \\
\text { Inferior }\end{array}$ & 3,17 & \\
\hline & & $\begin{array}{l}\text { Interior } \\
\text { Limite } \\
\text { Superior }\end{array}$ & 3,35 & \\
\hline & Mediana & & 3,33 & \\
\hline & Desvio Padrãc & & 0,78 & \\
\hline & Média & & 3,57 & 0,03 \\
\hline \multirow{4}{*}{$\begin{array}{l}\text { Escala de Atitudes } \\
\text { Frente ao Álcool, } \\
\text { ao Alcoolismo e ao } \\
\text { Alcoolista }\end{array}$} & \multirow[b]{2}{*}{ IC 95\% } & Limite & 3,52 & \\
\hline & & $\begin{array}{l}\text { Limite } \\
\text { Superior }\end{array}$ & 3,62 & \\
\hline & Mediana & & 3,63 & \\
\hline & \multicolumn{2}{|l|}{ Desvio Padrão } & 0,45 & \\
\hline
\end{tabular}

Fonte: CAPSad, São Paulo-SP, 2014. 


\subsection{ANÁLISE DESCRITIVA}

\subsubsection{O CAPSad na Perspectiva dos Profissionais dos CAPSad de São Paulo/SP}

No que se refere às condições de trabalho, desde que o profissional entrou no serviço, 37,5\% mencionaram que melhoraram pouco e $30,2 \%$ que melhoraram muito, o que demonstra uma melhora nas condições de trabalho, 92,4\% dos entrevistados não sofreram acidente de trabalho, como pode ser observado na tabela 4 .

Tabela 4: Condições e incômodos enfrentados no trabalho pelos profissionais dos CAPSad, São Paulo/SP $(n=288)$.

\begin{tabular}{|c|c|c|c|}
\hline Variáveis & & $\mathrm{N}$ & $\%$ \\
\hline \multirow{5}{*}{ Condições de Trabalho } & Pioraram & 29 & $10.1 \%$ \\
\hline & Não mudaram & 64 & $22.2 \%$ \\
\hline & Melhoraram pouco & 108 & $37.5 \%$ \\
\hline & Melhoraram muito & 87 & $30.2 \%$ \\
\hline & Total & 288 & $100.0 \%$ \\
\hline \multirow{3}{*}{$\begin{array}{l}\text { Falta de ferramenta } \\
\text { adequada para o } \\
\text { trabalho }\end{array}$} & Não & 154 & $53.5 \%$ \\
\hline & Sim & 134 & $46.5 \%$ \\
\hline & Total & 288 & $100.0 \%$ \\
\hline \multirow{3}{*}{ Falta de Segurança } & Não & 149 & $51.7 \%$ \\
\hline & Sim & 139 & $48.3 \%$ \\
\hline & Total & 288 & $100.0 \%$ \\
\hline \multirow{3}{*}{$\begin{array}{l}\text { Risco Permanente de } \\
\text { Vida }\end{array}$} & Não & 205 & $71.2 \%$ \\
\hline & Sim & 83 & $28.8 \%$ \\
\hline & Total & 288 & $100.0 \%$ \\
\hline \multirow{3}{*}{$\begin{array}{l}\text { Outras situações que } \\
\text { incomodam }\end{array}$} & Não & 178 & $61.8 \%$ \\
\hline & Sim & 110 & $38.2 \%$ \\
\hline & Total & 288 & $100.0 \%$ \\
\hline \multirow{3}{*}{$\begin{array}{l}\text { Acidente de trabalho nos } \\
\text { últimos } 6 \text { meses }\end{array}$} & Não & 266 & $92.4 \%$ \\
\hline & Sim & 22 & $7.6 \%$ \\
\hline & Total & 288 & $100.0 \%$ \\
\hline
\end{tabular}

Fonte: CAPSad, São Paulo-SP, 2014. 
Os itens que avaliam se os trabalhadores podem se atualizar discutir casos, e outras atividades que visam à melhoria da assistência prestada possuem uma avaliação positiva por parte dos trabalhadores. No que se relaciona à autonomia do trabalhador para escolher individualmente a forma de exercer o seu trabalho, 35,8\% referiram não ter essa autonomia, como pode ser observado na tabela 5.

Tabela 5: Visão do trabalhador acerca de sua autonomia no trabalho - Possibilidades de trabalho no CAPSad, São Paulo/SP ( $n=288)$.

\begin{tabular}{llcc}
\hline Em seu Trabalho Você Pode & & $\mathrm{N}$ & $\%$ \\
\hline \multirow{2}{*}{$\begin{array}{l}\text { Escolher Individualmente a Forma } \\
\text { de Fazer Suas Atividades }\end{array}$} & Não & 103 & $35.8 \%$ \\
& Sim & 185 & $64.2 \%$ \\
& Total & 288 & $100 \%$ \\
\hline Escolher de Forma Coletiva/Em & Não & 20 & $6.9 \%$ \\
Equipe a Forma de Fazer Suas & Sim & 268 & $93.1 \%$ \\
Atividades & Total & 288 & $100 \%$ \\
\hline \multirow{3}{*}{ Fazer Cursos } & Não & 67 & $23.3 \%$ \\
\hline \multirow{2}{*}{ Realizar Outras Atividades de } & Sim & 221 & $76.7 \%$ \\
Organização & Total & 288 & $100 \%$ \\
\hline \multirow{3}{*}{ Conversar com os Colegas } & Não & 66 & $22.9 \%$ \\
& Sim & 222 & $77.1 \%$ \\
\hline \multirow{3}{*}{ Usar Suas Ideias } & Total & 288 & $100 \%$ \\
\hline \multirow{2}{*}{ Discutir Casos com os Colegas } & Não & 5 & $1.7 \%$ \\
& Sim & 283 & $98.3 \%$ \\
& Total & 288 & $100 \%$ \\
\hline
\end{tabular}

Fonte: CAPSad, São Paulo-SP, 2014.

No que diz respeito à satisfação da equipe com o seu trabalho, qualidade do serviço oferecido, participação no serviço, condições de 
trabalho, relacionamento com o serviço, e satisfação global com o serviço, todas os escores médios medidos pela escala SATIS foram superiores a 3 . Esses escores, que variam de 1 a 5 , indicam que os trabalhadores avaliam positivamente a sua satisfação como pode ser observado na tabela 6 .

Tabela 6: Médias e desvios padrão do Escore Global e de cada fator da escala SATIS-BR, segundo os profissionais dos CAPSad, São Paulo/SP ( $n=288)$.

\begin{tabular}{|c|c|c|c|}
\hline \multirow{6}{*}{$\begin{array}{l}\text { Satisfação da Equipe com } \\
\text { Relação à Qualidade dos } \\
\text { Serviços Oferecidos aos } \\
\text { Usuários }\end{array}$} & \multicolumn{2}{|l|}{ Média } & \multirow{2}{*}{$\begin{array}{l}3,98 \\
3,92\end{array}$} \\
\hline & \multirow{3}{*}{ IC 95\% } & Limite Inferior & \\
\hline & & Limite & 4.03 \\
\hline & & Superior & \\
\hline & Mediana & & 4,00 \\
\hline & Desvio Padrão & & 0,48 \\
\hline \multirow{5}{*}{$\begin{array}{l}\text { Satisfação da Equipe com } \\
\text { relação à sua Participação no } \\
\text { serviço. }\end{array}$} & Média & & 3,63 \\
\hline & \multirow[b]{2}{*}{ IC 95\% } & Limite Inferior & 3,56 \\
\hline & & $\begin{array}{l}\text { Limite } \\
\text { Superior }\end{array}$ & 3,71 \\
\hline & Mediana & & 3,71 \\
\hline & Desvio Padrão & & 0,65 \\
\hline \multirow{5}{*}{$\begin{array}{l}\text { Satisfação da Equipe com } \\
\text { relação às condições de } \\
\text { trabalho no serviço. }\end{array}$} & Média & & 3,98 \\
\hline & \multirow[b]{2}{*}{ IC 95\% } & Limite Inferior & 3,90 \\
\hline & & $\begin{array}{l}\text { Limite } \\
\text { Superior }\end{array}$ & 4,06 \\
\hline & Mediana & & 4,00 \\
\hline & Desvio Padrão & & 0,67 \\
\hline \multirow{5}{*}{$\begin{array}{l}\text { Satisfação da Equipe a } \\
\text { respeito do seu } \\
\text { relacionamento no serviço. }\end{array}$} & Média & & 3,88 \\
\hline & IC 95\% & Limite Inferior & 3,80 \\
\hline & & $\begin{array}{l}\text { Limite } \\
\text { Superior }\end{array}$ & 3,96 \\
\hline & Mediana & & 4,00 \\
\hline & Desvio Padrão & & 0,70 \\
\hline \multirow{5}{*}{$\begin{array}{l}\text { Grau de Satisfação Global da } \\
\text { Equipe com o Serviço de } \\
\text { Saúde Mental }\end{array}$} & Média & & 3,77 \\
\hline & & Limite Inferior & 3,71 \\
\hline & IC 95\% & $\begin{array}{l}\text { Limite } \\
\text { Superior }\end{array}$ & 3,83 \\
\hline & Mediana & & 3,81 \\
\hline & Desvio Padrão & & 0,48 \\
\hline
\end{tabular}

Fonte: CAPSad, São Paulo-SP, 2014. 
Quanto à abordagem que utilizam, metade dos trabalhadores refere que utiliza tanto a Redução de Danos quanto a abstinência total em sua prática no CAPSad. Quando questionados sobre o principal motivo pelo qual o tratamento no CAPSad é procurado, $91 \%$ dos trabalhadores afirma que é por conta do impacto global na vida relacionado ao consumo prejudicial de álcool e/ou outras drogas.

Tabela 7: Visão dos trabalhadores sobre a razão principal para o tratamento e abordagem utilizada no CAPSad.

\begin{tabular}{|c|c|c|c|}
\hline \multirow{2}{*}{\multicolumn{4}{|c|}{$\begin{array}{r}\text { Contagem } \\
\text { Principal motivo para procura por tratamento }\end{array}$}} \\
\hline & & & \\
\hline O consumo de álcool e & Não & 50 & $17,4 \%$ \\
\hline \multirow[t]{2}{*}{ outras drogas } & Sim & 238 & $82,6 \%$ \\
\hline & Total & 288 & $100,0 \%$ \\
\hline A gravidade do consumo & Não & 54 & $18,8 \%$ \\
\hline \multirow{2}{*}{ de álcool e outras drogas } & Sim & 234 & $81,2 \%$ \\
\hline & Total & 288 & $100,0 \%$ \\
\hline \multirow{4}{*}{$\begin{array}{l}\text { O impacto global na vida } \\
\text { relacionado ao consumo } \\
\text { prejudicial de álcool ou } \\
\text { outras drogas } \\
\text { Modalidade de tratamento }\end{array}$} & Não & 25 & $8,7 \%$ \\
\hline & Sim & 263 & $91,3 \%$ \\
\hline & Total & 288 & $100,0 \%$ \\
\hline & & & \\
\hline \multirow{3}{*}{ Redução de Danos } & Não & 161 & $55,9 \%$ \\
\hline & Sim & 127 & $44,1 \%$ \\
\hline & Total & 288 & $100,0 \%$ \\
\hline \multirow[t]{3}{*}{ Abstinência total } & Não & 283 & $98,3 \%$ \\
\hline & Sim & 5 & $1,7 \%$ \\
\hline & Total & 288 & $100,0 \%$ \\
\hline \multirow[t]{3}{*}{ As duas modalidades } & Não & 144 & $50,0 \%$ \\
\hline & Sim & 144 & $50,0 \%$ \\
\hline & Total & 288 & $100,0 \%$ \\
\hline \multirow[t]{3}{*}{ Não Sabe } & Não & 276 & $95,8 \%$ \\
\hline & Sim & 12 & $4,2 \%$ \\
\hline & Total & 288 & $100,0 \%$ \\
\hline
\end{tabular}

Fonte: CAPSad, São Paulo-SP, 2014. 


\subsection{ANÁLISE INFERENCIAL}

Para a análise dos determinantes das atitudes dos trabalhadores na Escala de Atitudes Frente ao Álcool, ao Alcoolismo e ao Alcoolista (EAFAAA) optamos por metodologia semelhante à utilizada na seção anterior para definir a inclusão das variáveis nos modelos de regressão. Em primeiro lugar dividimos as variáveis em três classes: descrição sociodemográfica dos trabalhadores, perfil do trabalhador e processo de trabalho.

$\mathrm{Na}$ primeira etapa da pesquisa, incluímos cada uma das variáveis independentes em modelos univariados OLS. Incluímos no modelo OLS múltiplo final as variáveis com valor de $p \leq 0,3$. A Tabela 8 apresenta os resultados dos modelos lineares univariados. A tabela 9 apresenta os resultados do modelo múltiplo. 
Tabela 8: Modelos univariados para atitudes dos profissionais.

\begin{tabular}{|c|c|c|c|}
\hline Variável & B & & $\mathbf{R}^{2}$ \\
\hline Sexo & 0,13 & 0,02 & 0,01 \\
\hline Raça/cor & 0,16 & 0,00 & 0,03 \\
\hline Idade & 0,00 & 0,74 & 0,00 \\
\hline \multicolumn{4}{|l|}{$\begin{array}{l}\text { Trabalha em CAPSad } \\
\text { há } 1 \text { ano (categoria de } \\
\text { referência) }\end{array}$} \\
\hline $\begin{array}{l}\text { Trabalha em CAPSad } \\
\text { entre } 2 \text { a } 4 \text { anos }\end{array}$ & 0,04 & 0,507 & 0,040 \\
\hline $\begin{array}{l}\text { Trabalha em CAPSad } \\
\text { entre } 5 \text { a } 7 \text { anos }\end{array}$ & 0,14 & ,127 & \\
\hline $\begin{array}{l}\text { Trabalha em CAPSad } \\
\text { entre } 8 \text { a } 10 \text { anos }\end{array}$ & 0,25 & 031 & \\
\hline $\begin{array}{l}\text { Trabalha em CAPSad } \\
\text { há mais de } 10 \text { anos }\end{array}$ & 0,24 & ,006 & \\
\hline \multicolumn{4}{|l|}{$\begin{array}{l}\text { Profissionais de nível } \\
\text { superior (categoria de } \\
\text { referência) }\end{array}$} \\
\hline $\begin{array}{l}\text { Administrativo/Manuten } \\
\text { ção }\end{array}$ &,- 577 & ,000 & 290 \\
\hline $\begin{array}{l}\text { Profissionais de nível } \\
\text { técnico em saúde }\end{array}$ &,- 394 & ,000 & \\
\hline Oficineiros &,- 169 & ,083 & \\
\hline \multicolumn{4}{|l|}{$\begin{array}{l}\text { Até } 3 \text { salários mínimos } \\
\text { (categoria de } \\
\text { referência) }\end{array}$} \\
\hline $\begin{array}{l}\text { de } 4 \text { a } 7 \text { salários } \\
\text { mínimos }\end{array}$ & ,225 & ,000 & 155 \\
\hline $\begin{array}{l}\text { de } 8 \text { a } 11 \text { salários } \\
\text { mínimos }\end{array}$ & ,416 &, 000 & \\
\hline $\begin{array}{l}\text { de } 12 \text { a } 15 \text { salários } \\
\text { mínimos }\end{array}$ & ,536 & ,000 & \\
\hline $\begin{array}{l}\text { mais de } 16 \text { salários } \\
\text { mínimos }\end{array}$ &, 390 & ,001 & \\
\hline Condições de trabalho &,- 054 &, 051 & ,013 \\
\hline Estado civil &,- 053 & ,314 & ,004 \\
\hline $\begin{array}{l}\text { Incômodos } \\
\text { evidenciados no } \\
\text { traBalho }\end{array}$ &, 073 & 001 & ,039 \\
\hline $\begin{array}{l}\text { Possibilidades de seu } \\
\text { trabalho }\end{array}$ &, 111 &, 000 & ,133 \\
\hline \multicolumn{4}{|l|}{$\begin{array}{l}\text { Redução de Danos } \\
\text { (categoria de } \\
\text { referência) }\end{array}$} \\
\hline Abstinência total &,- 376 & ,054 & ,091 \\
\hline As duas modalidades &,- 043 & 409 & \\
\hline Não Sabe &,- 652 & ,000 & \\
\hline Satisfação Global &,- 057 & 287 & ,004 \\
\hline
\end{tabular}


Razões pelas quais acreditam que os usuários buscam o serviço O consumo de álcool e outras drogas A gravidade do consumo de álcool e outras drogas

O impacto global na vida do uso de álcool e outras drogas Possui pós graduação $\begin{array}{lll}-, 156 \quad 066 & , 067\end{array}$ $-, 066 \quad, 661$ ,001 , , 873

Fonte: CAPSad, São Paulo-SP, 2014.

Como pode ser observado na tabela 8, apenas as variáveis idade e estado civil não obtiveram valor de $p \leq 0,3$ e foram excluídas do modelo múltiplo.

Após regressão múltipla, evidenciou-se que os profissionais que trabalham no CAPSad no período de 8 a 10 anos e aqueles profissionais que possuem uma análise de que o seu trabalho lhe traz mais incômodos, possuem atitudes mais positivas. Os profissionais do administrativo, manutenção e técnicos em saúde possuem atitudes mais negativas, considerando como estatisticamente significantes os valores de $p \leq 0,05$. Estes resultados podem ser evidenciados na tabela 9 abaixo. 
Tabela 9: Modelo múltiplo para atitudes dos profissionais.

CONSTANTE

SEXO

RAÇA/COR

TRABALHA EM CAPSAD HÁ 1 ANO

(CATEGORIA DE REFERÊNCIA)

TRABALHA EM CAPSAD ENTRE 2 A 4

ANOS

TRABALHA EM CAPSAD ENTRE 5 A 7

ANOS

TRABALHA EM CAPSAD ENTRE 8 A 10

ANOS

TRABALHA EM CAPSAD HÁ MAIS DE 10 ANOS

PROFISSIONAIS DE NÍVEL SUPERIOR (CATEGORIA DE REFERÊNCIA)

ADMINISTRATIVO/MANUTENÇÃO

PROFISSIONAIS DE NIVEL TÉCNICO EM

SAÚDE

OFICINEIROS

DE 1 A 3 SALÁRIOS MÍNIMOS

DE 4 A 7 SALÁRIOS MÍNIMOS

DE 8 A 11 SALÁRIOS MÍNIMOS

DE 12 A 15 SALÁRIOS MÍNIMOS

MAIS DE 16 SALÁRIOS MÍNIMOS

CONDIÇÕES DE TRABALHO

INCOOMODOS EVIDENCIADOS NO

TRABALHO

POSSIBILIDADES DE SEU TRABALHO

REDUÇÃO DE DANOS (CATEGORIA DE REFERÊNCIA)

ABSTINÊNCIA TOTAL

AS DUAS MODALIDADES

NÃO SABE

SATISFAÇÃO GLOBAL

RAZÕES PELAS QUAIS ACREDITAM QUE

OS USUÁRIOS BUSCAM O SERVIÇO

O CONSUMO DE ÁLCOOL E OUTRAS DROGAS

\begin{tabular}{|rr}
\multicolumn{1}{|l}{ B } & \multicolumn{1}{l}{$\begin{array}{l}\text { Valor } \\
\text { de } p .\end{array}$} \\
3,232 & $p \leq 0,001$ \\
0,054 & 0,29 \\
0,011 & 0,82 \\
& \\
0,008 & 0,89 \\
0,111 & 0,17 \\
0,224 & 0,03 \\
0,104 & 0,22
\end{tabular}

$-0,39 p \leq 0,001$

$-0,29 p \leq 0,001$

$\begin{array}{ll}-0,07 & 0,54\end{array}$

$-0,08 \quad 0,31$

$-0,03 \quad 0,73$

$0,009 \quad 0,93$

$0,046 \quad 0,69$

$-0,02 \quad 0,88$

$-0,02 \quad 0,38$

$0,045 \quad 0,05^{\star}$

$0,028 \quad 0,15$

$-0,31 \quad 0,08$

$-0,04 \quad 0,46$

$-0,25 \quad 0,06$

$0,09 \quad 0,13$

$-0,06 \quad 0,36$ 

A GRAVIDADE DO CONSUMO DE ÁLCOOL
E OUTRAS DROGAS
O IMPACTO GLOBAL NA VIDA DO USO DE
0,034
0,61 ÁLCOOL E OUTRAS DROGAS POSSUI PÓS GRADUAÇÃO
$-0,09 \quad 0,31$
$0,023 \quad 0,75$

Fonte: CAPSad, São Paulo-SP, 2014. 


\section{DISCUSSÃO}

Em relação ao perfil dos profissionais que trabalham em CAPSad, constatou-se a prevalência do sexo feminino, casada, adultas jovens e com nível de educação superior. Outros estudos nacionais que analisaram o perfil sócio demográfico dos trabalhadores de saúde mental encontraram percentuais semelhantes 61-63

No que se refere ao tempo de trabalho, observou-se que quase a metade dos profissionais trabalham em CAPSad há pouco tempo (entre 2 a 4 anos), informação corroborada em outro estudo 64 .

Sobre o número de vínculos trabalhistas, a maioria dos trabalhadores apontou o vínculo apenas com o CAPSad, o que difere de outros estudos, no quais, a maioria dos participantes que trabalham na área de saúde mental relatou ter outro emprego ${ }^{61-63}$.

Ao se analisar a atitude dos profissionais dos CAPSad, observou-se que, de uma forma geral, os profissionais apresentaram tendência a atitudes positivas frente ao álcool, ao alcoolismo e ao alcoolista. Analisando cada fator separadamente, observou-se uma atitude positiva dos profissionais frente aos Fatores 1 (trabalhar e relacionar-se com o alcoolista), 2 (atitudes frente ao alcoolista) e 4 (atitudes frente ao uso do álcool) e atitudes menos positivas frente ao Fator 3 (etiologia do alcoolismo).

A tendência positiva no fator 1 pode estar relacionada ao fato desses profissionais trabalharem em serviços especializados no cuidado ao adicto de álcool e outras drogas, já que estudos com enfermeiros demonstram que aqueles que trabalhavam diretamente com alcoolistas apresentavam atitudes positivas frente ao usuário ${ }^{65}$.

Resultado semelhante no que diz respeito ao fator 2 foi encontrado em estudo anterior ao identificar que os enfermeiros de hospitais gerais percebem os alcoolistas como uma pessoa sensível, sozinha e com graves dificuldades emocionais. Essa percepção pode 
auxiliar o enfermeiro no reconhecimento de que o alcoolista é alguém que está doente e precisa de ajuda, contribuindo para o estabelecimento do relacionamento interpessoal ${ }^{40}$.

Já o fato desses profissionais apresentarem atitudes menos positivas frente à etiologia do alcoolismo (fator 3) pode estar relacionado à formação, uma vez que estudo identificou que a maior parte dos enfermeiros que atuam em CAPSad, no município de São Paulo, carece de formação específica na área das SPAS e não recebeu preparo adequado para atuação com o usuário de SPAS durante a graduação em enfermagem ${ }^{45,66}$.

Resultados semelhantes foram encontrados em estudo que investigou a atitude de estudantes de psicologia acerca do álcool, alcoolismo e alcoolista ${ }^{67}$.

Outra pesquisa, realizada no Brasil, evidenciou que os estudantes tinham uma atitude positiva frente ao dependente de substâncias psicoativas, pois a maioria rejeitou o estereótipo de que estes são desagradáveis de se trabalhar, entretanto o alcoolismo estava relacionado à fraqueza de caráter ${ }^{6}$.

Já outro estudo realizado com estudantes de enfermagem encontrou resultado oposto, ou seja, evidenciou-se tendência a atitudes negativas desses estudantes frente ao alcoolismo, ao alcoolista e à bebida alcoólica e não apenas no fator $3{ }^{42}$.

Os resultados em relação aos estudantes é um fato preocupante, uma vez que os estudantes serão os futuros profissionais e a predominância da tendência a atitudes negativas frente ao problema poderão ser concretizadas em um cuidado sem qualidade e carregado de preconceito.

Estudo correlacionou a tendência de atitudes negativas à pouca atenção dada à temática durante a formação, constatando-se a necessidade de que maior importância seja dada a essa problemática $^{42}$. 
Muitas condições de saúde, sobretudo a saúde mental e a dependência SPAS, são estigmatizadas pela população e até mesmo pelos profissionais de saúde. Pesquisas internacionais realizadas com profissionais de saúde, na área da saúde mental, também têm apontado atitudes negativas por parte dos profissionais.

Estudo examinou as atitudes de médicos e enfermeiros e seu impacto em relação a pessoas com deficiência no Butão. Encontraram que os escores médios de ambas as profissões foram menores do que os de outros estudos. Médicos e enfermeiros butaneses parecem manter atitudes menos positivas em relação às pessoas com deficiência do que nos países ocidentais ${ }^{69}$.

Estudo sueco que buscou avaliar as atitudes de profissionais que atuavam em serviços de saúde mental, bem como de seus pacientes, identificou que as atitudes negativas foram prevalentes tanto entre os profissionais, quanto entre os pacientes. Funcionários que trabalhavam com pacientes psicóticos ou em regime de internamento tiveram as atitudes mais negativas ${ }^{70}$.

Outro estudo comparou as atitudes do público em geral dos EUA e de profissionais de saúde mental sobre a competência e a periculosidade percebida por portadores de transtorno mental. Embora os profissionais apresentassem atitudes mais positivas do que o público em geral, os estereótipos associados ao transtorno mental persistiu em ambos os grupos ${ }^{71}$.

Conforme visto, apesar dos avanços obtidos com a Reforma Psiquiátrica em diversos Países, ainda na atualidade é possível identificar atitudes negativas dos profissionais que trabalham na área da saúde mental e de álcool e outras drogas. Entendemos que a estigmatização desses indivíduos ocorre quando pessoas atribuem rótulos e estereótipos negativos a determinados comportamentos.

Tal condição influencia direta ou indiretamente a condição de saúde da pessoa estigmatizada, levando a diversas consequências, inclusive ao agravamento da situação. Pois o estigma se estende para 
além do individuo, passando para as pessoas que se relacionam diretamente com eles, seus familiares, amigos, e indiretamente os profissionais da área da saúde, permitindo também à sociedade considera-los uma pessoa diferente.

O estereótipo negativo que cerca o paciente alcoolista e o alcoolismo exerce forte influência nas atitudes dos profissionais, contribuindo para que estas se tornem mais negativas ${ }^{32}$.

Estudos experimentais sobre as atitudes dos enfermeiros evidenciaram o predomínio de concepções morais e condenatórias por parte de enfermeiros, que tende a culpar o alcoolista pela sua doença ${ }^{32}$.

Atribuir o alcoolismo à falta de vontade do indivíduo em parar de consumir a substância é uma visão reducionista, embora ainda encontremos uma grande parcela de enfermeiros que consideram o alcoolista um sujeito imoral, fraco e com baixa possibilidade de recuperação ${ }^{37,56}$.

Os resultados nos permitem inferir que a pessoa do alcoolista é mais aceita pelos profissionais dos CAPSad que sua doença, o que pode estar relacionado ao preconceito que envolve o alcoolismo e suas complicações, que na maioria das vezes é visto como uma fraqueza moral e não como uma doença crônica que, quando tratada, pode ser controlada como qualquer outra.

Diante desse resultado, podemos refletir acerca de uma contradição, pois ao mesmo tempo em que os profissionais consideram o uso abusivo de SPAS uma doença que precisa ser tratada, eles culpam o alcoolista pelo uso e pelas consequências advindas do uso.

Entendemos que a etiologia do alcoolismo pode estar relacionada à ideia transmitida culturalmente e socialmente de que o bebedor é um homem fraco e sem caráter, conforme ocorria no inicio 
do Século XX e se perpetua até os dias atuais, como um resquício do modelo moral.

Pois as atitudes negativas sobre determinado comportamento social seriam formadas pelas normas sociais, que variam de acordo com o grupo em que os indivíduos estão inseridos e com o contexto social, cultural e histórico em que cada um se encontra.

Entretanto as atitudes de enfermeiros frente ao abuso de substâncias parecem ser mais positivas na atualidade do que há três décadas, corroborando os resultados desse estudo ${ }^{32}$.

Analisamos, por meio de regressão múltipla, a influência relativa de diversas variáveis na determinação das atitudes dos profissionais do CAPSad. Dentre as variáveis estudadas, observouse que os profissionais que trabalham entre 8 a 10 anos, possuem atitudes mais positivas em relação a profissionais com menos tempo de atuação.

Esse resultado pode estar relacionado à experiência que os profissionais adquirem no decorrer do tempo de trabalho na assistência direta ao paciente, bem como ao compartilhamento do conhecimento e das vivências interdisciplinares da equipe de saúde.

Estudos encontraram que uma das fontes de conhecimento é a troca de experiências que ocorre entre os membros da equipe, dentro do próprio serviço ${ }^{45,66}$.

Outro estudo realizado com enfermeiros indicou que fatores pessoais e experiência de trabalho útil, foram considerados significativos, dentre os fatores que influenciam na aquisição da competência clínica ${ }^{72}$.

A prática constante do cuidado permite adquirir cada vez mais habilidades, além de mostrarem atitudes mais positivas frente ao usuário de álcool e melhor conhecimento sobre a temática ${ }^{73,74}$.

Portanto, podemos inferir que quanto maior o tempo de experiência profissional na área de álcool e outras drogas, possivelmente maior conhecimento e competência para o manejo 
clínico dessa problemática, o que possibilita atitudes mais positivas frente ao álcool, alcoolismo e alcoolista.

Outro determinante importante na atitude dos profissionais foi em relação aos incômodos, ou seja, os profissionais que possuem uma análise de que o seu trabalho lhe traz mais incômodos, possuem atitudes mais positivas frente ao álcool, alcoolismo e alcoolista.

A percepção do profissional acerca do equipamento de saúde no qual atua, permite diagnosticar as características do serviço, segundo a ótica dos próprios funcionários em relação aos seus aspectos administrativos e no que diz respeito à relação profissionalusuário ${ }^{75,76}$.

Não foram encontrados estudos que explorassem essa correlação. Estudos nacionais tem discutido a percepção do profissional sobre a qualidade do serviço oferecido.

Em 2012 identificou-se que as percepções de psicólogos que trabalham em serviços públicos de saúde, sobre os fatores que contribuem e os que prejudicam seu bem-estar no trabalho (BET). Dentre os fatores que contribuem para o BET foram citados: a qualidade e o relacionamento com a equipe $(30,5 \%)$, a satisfação e a realização no trabalho $(22,9 \%)$ e o contato com o paciente $(21,7 \%)$. Já os fatores que prejudicam o BET foram: os problemas de gestão/instituição $(28,3 \%)$, os problemas com a equipe $(24,2 \%)$ e a falta de condições de trabalho $(19,4 \%)$.

Estudo em dez municípios do Estado do Ceará, buscando identificar um conjunto de aspectos referentes à estrutura e ao processo do serviço, que deveria qualificar o PSF. Foram entrevistados médicos e enfermeiros das equipes, coordenadores do PSF, secretários de saúde e usuários. Os profissionais citaram quatro elementos definidores da qualidade: a relação profissional-paciente, onde se faz necessário estabelecer um vínculo de confiança entre usuário e profissional que favoreça a inserção da equipe no ambiente de vida do paciente; a estrutura física que nem sempre é adequada 
às necessidades do serviço e nem sempre dotada de um equipamento mínimo; a questão da educação em saúde que exige uma melhor implementação; o nível de capacitação dos profissionais que compõem a equipe do Programa e a necessidade de um maior número de profissionais frente à demanda bem superior, ao que preconiza o MS, que cada Unidade Básica de Saúde tem ${ }^{77}$.

Estudo encontrou em sua pesquisa, que para os profissionais a função da qualidade nas unidades de saúde da família, estão relacionadas à: educação continuada, motivação profissional, incentivo financeiro, rotatividade profissional ${ }^{75}$.

Estudo que objetivou verificar como os enfermeiros de uma instituição pública de saúde, com referência em traumatologia, procedem à avaliação do processo de trabalho a partir das demandas dos usuários registradas no setor de ouvidoria, encontrou que há a necessidade de rever o processo de trabalho da equipe, bem como maior diálogo entre a equipe ${ }^{78}$.

Os resultados desta pesquisa sugerem que profissionais mais críticos com o seu cotidiano de trabalho, apresentam tendência a atitudes positivas frente ao álcool, ao alcoolismo e ao alcoolista, o que pode estar relacionado ao fato desses profissionais se apropriarem da dinâmica existente nos CAPSad, questionando incoerências técnicas, a gestão e a organização do serviço, bem como o seu processo de trabalho.

Possivelmente esses profissionais tiveram acesso ao conteúdo relacionado ao uso de álcool e outras drogas em seus cursos de formação profissional, além de possuírem mais experiência de trabalho e consequentemente apresentarem atitudes mais positivas frente ao álcool, alcoolismo e alcoolista.

Nesse sentido, as expectativas colocadas pelo novo modo de produção exige uma formação crítica-reflexiva de profissionais da área da saúde. Essa formação deve objetivar formar um profissional orientado para a indagação, para a reflexão na ação, capaz de 
problematizar e, portanto não alienado; capaz de evitar o verbalismo, - congelamento do real, a adaptação às estruturas, a compartimentalização do saber que contribui para a falta de domínio do processo, do produto e do sentido do próprio trabalho ${ }^{79}$.

Acreditamos que profissionais que questionam acerca do funcionamento do serviço, da estrutura física para realizar atendimentos, sobre as condições de trabalho oferecidas e em relação ao próprio processo de trabalho da equipe, são indivíduos mais críticos e que se incomodam com algumas situações, realizando movimentos na instituição com o fim de diminuir esses incômodos.

Outro resultado obtido refere que profissionais administrativos, de manutenção e técnicos em saúde possuem atitudes mais negativas do que os profissionais de nível superior.

O fato de ter-se observado que os profissionais com nível fundamental e médio apresentam uma tendência a atitudes mais negativas do que aqueles que possuem graduação, aponta para a necessidade da inclusão do tema álcool e outras drogas na formação dos profissionais de nível médio, em especial, ao profissional da equipe de enfermagem, já que estão em maior número nos CAPSad.

Há evidências na literatura de que enfermeiros com pós graduação e que tiveram acesso à discussão do tema relacionado ao AOD durante a formação, tendem a apresentar atitudes mais positivas frente ao álcool, ao alcoolismo e ao alcoolista ${ }^{42}$.

O impacto positivo da formação e do conhecimento global sobre questões relativas ao uso de álcool e outras drogas nas atitudes dos profissionais que lidam com essa população, também foi ressaltado em outra pesquisa ${ }^{80}$.

Acerca da formação, já em 1998, estudo alertava acerca da separação entre a dimensão técnica e política na operacionalização das propostas pensadas pelos educadores da área da saúde. As autoras falam sobre a cisão existente entre a teoria e a prática, 
enfatizando que quando se trabalha a teoria se permite elucubrações e a reflexão política, entretanto ao se trabalhar a prática congela-se a política e o que importa é o exercício da prática profissional, nos moldes do ensino tradicional, porém competente para os fins a que, dissimuladamente, se propõe ${ }^{79}$.

Em 2013 sinalizou-se a carência de preparo educacional durante a graduação em relação à temática do álcool, ou a falta de abordagem apropriada do conteúdo nas universidades, devido à deficiência do conteúdo nos currículos de graduação ${ }^{42}$.

Sobre as dificuldades verificadas na proposição de currículos de enfermagem que contemplem de forma adequada a temática das substâncias psicoativas no Brasil, estudo ressaltou a iniciativa de possibilitar a experiência clínica em serviço especializado de álcool e drogas, mesmo que limitada pelo tempo e pela não sistematização do tema no currículo da graduação, pois a essa inclusão mostrou ser de extrema importância para a consolidação do conteúdo e das mudanças de paradigma, o que leva o estudante a uma reflexão sobre seus valores e crenças durante a graduação, o que, em última análise, repercute na minimização das atitudes negativas, dos preconceitos e estereótipos atribuídos a essas pessoas ${ }^{81}$.

Outro estudo sugere que o programa educativo sobre álcool e drogas exerceu impacto nas atitudes dos estudantes de enfermagem, uma vez que no pós-teste a maioria dos participantes demonstrou atitudes mais positivas frente ao dependente químico e estava mais otimista, considerando a dependência de álcool e drogas, como uma doença tratável ${ }^{68,82}$.

O preparo e o conhecimento estão diretamente relacionados às atitudes positivas frente ao paciente alcoolista, estudos sugerem que o nível de aproveitamento do conhecimento deve ser maior que $50 \%$, para que a formação ofertada tenha impacto nas atitudes de enfermeiros frente a problemas relacionados ao uso e abuso de álcool 83. 
No caso de profissionais de saúde que já se encontram na assistência voltada a essa população, sugerimos como principal estratégia de aprimoramento a Educação Permanente (EP), que têm tem a incumbência de corrigir os pontos considerados negativos na atuação dos novos profissionais, além de auxiliar a equipe na problematização do processo de trabalho, considerando as necessidades de formação e desenvolvimento dos trabalhadores, de forma que sejam pautadas pelas necessidades de saúde das pessoas e populações.

A EP é a aprendizagem no trabalho, onde o aprender e o ensinar se incorporam ao cotidiano das pessoas, das organizações e do trabalho, baseando-se na aprendizagem significativa e na possibilidade de transformar as práticas profissionais, pois a EP é planejada a partir dos problemas enfrentados na realidade, considerando os conhecimentos $e$ as experiências que os profissionais envolvidos já dispõem ${ }^{84}$.

Estudo refere sobre a importância de capacitação técnica dos profissionais envolvidos, tanto no que diz respeito ao conhecimento sobre as substâncias psicoativas - seus efeitos, dosagens, danos, formas de utilização - bem como as propostas teóricas que pretendem compreender o porquê do uso, terapêuticas, fatores de risco e de proteção, populações vulneráveis e políticas públicas, dentre outros aspectos, indispensáveis a todos os profissionais que lidam com essa população especifica ${ }^{85}$.

Há ainda a necessidade do profissional de saúde que trabalha com usuários de SPAS, olhar para si mesmo: suas crenças, valores, preconceitos, escolhas do enfoque teórico sobre a questão, engajamento e as condições da prática, considerando que a concepção que os trabalhadores apresentam acerca do usuário de substâncias psicoativas, influenciará na atitude positiva ou negativa, pela qual este se relacionará com o mesmo e determinará a qualidade e a efetividade da assistência prestada ${ }^{86}$. 
Neste sentido, afirmamos que o atendimento aos usuários de álcool e outras drogas é provavelmente aquele que gera maior mobilização por parte dos profissionais de saúde, independente da categoria profissional. Sobretudo, quando consideramos que o atendimento dessa situação é influenciado pela ambiguidade de valores, concepções e representações sociais predominantemente estigmatizadas do senso comum, que consideram tal questão como um problema moral relacionado á instabilidade emocional e falta de força de vontade dos usuários.

Portanto, é fundamental que o profissional de saúde reflita acerca de suas atitudes frente ao usuário de SPAS e ofereça cuidados sem julgamento ao indivíduo. Para isso faz-se necessário o reconhecimento das fontes de suas atitudes; explorar como suas atitudes afetam os cuidados prestados ao paciente complementando com autoconsciência e mudança de certas atitudes comprovadas como negativas ${ }^{38}$.

Dessa forma entendemos que os conhecimentos compartilhados entre graduandos, docentes, profissionais da saúde e comunidade precisam ser revistos e trabalhados durante todo o processo de formação acadêmica, buscando formar profissionais comprometidos com a população, com a transformação da realidade e com a mudança da representação que a sociedade tem acerca desses usuários. 


\section{LIMITAÇÕES DO ESTUDO}

O presente estudo foi realizado na cidade de São Paulo, com profissionais de 12 CAPSad, compreendendo todas as regiões da cidade, podendo os seus resultados, portanto, ser generalizados apenas para o contexto do cuidado aos usuários de álcool e outras drogas na cidade de São Paulo. Sugerimos que estudos em CAPSad de outras localidades avaliem as atitudes dos profissionais frente ao álcool, alcoolismo e alcoolista.

Apesar de não ter havido recusa por parte dos profissionais abordados para serem entrevistados, tivemos 61 perdas. Essas perdas somam $17 \%$ das entrevistas que pretendíamos realizar. Profissionais em licença, férias e afastados não foram entrevistados. Nos preocupamos, principalmente, com o fato de não termos dados sobre os afastamentos, o que pode ser de interesse ao objeto de estudo da presente tese. Sugerimos que estudos que avaliem os afastamentos e licenças dos trabalhadores de CAPSad sejam realizados no futuro. 


\section{CONCLUSÕES}

Profissionais dos CAPSad que sentem-se mais incomodados com os problemas no trabalho são aqueles que possuem atitudes mais positivas frente ao Álcool, Alcoolismo e alcoolista. Essas pessoas que possuem uma avaliação mais crítica do serviço, buscando melhorias para a assistência no CAPSad, políticas implementadas nos serviços.

Profissionais de nível superior também possuem atitudes mais positivas quando comparados aos profissionais do administrativo, manutenção e nível técnico de saúde dos serviços. As universidades, ainda que com uma variação muito grande de investimento financeiro e em horas de estudo relacionados ao álcool e outras drogas, trazem esse conteúdo para discussão com os estudantes, trazendo uma bagagem intelectual importante para a atuação no CAPSad.

A mesma formação não é dada em cursos básicos que formam os profissionais de nível administrativo, manutenção e, o que é mais grave, para os técnicos da área de saúde. A formação de base desses cursos precisa incluir nos currículos a temática sobre o uso de álcool e outras drogas. Os cursos de técnicos de saúde também devem integrar ao seu currículo conteúdos obrigatórios relacionados ao cuidado dessa população. Entretanto, cabe também aos serviços exercer um papel educativo, por meio da educação permanente, para preparar as pessoas que são selecionadas para trabalhar em CAPSad, visando melhores atitudes desses profissionais em relação à população atendida.

Profissionais que trabalham de 8 a 10 anos nos CAPSad possuem melhores atitudes. No decorrer do período de trabalho no CAPSad os profissionais buscam especializar-se e criam vínculos com os usuários, bem como convivem com os outros profissionais da equipe multidisciplinar e acabam desenvolvendo um pensamento 
mais crítico que possivelmente impacta positivamente no seu processo de trabalho. Esses fatores combatem o estigma frente ao usuário de álcool, tendo impacto direto em melhores atitudes frente ao álcool, alcoolismo e alcoolista.

Profissionais mais críticos, reflexivos, que tiveram acesso ao conteúdo relacionado ao uso de álcool e outras drogas em seus cursos de formação profissional, e que possuem mais experiência de trabalho possuem atitudes mais positivas frente ao álcool, alcoolismo e alcoolista. Esses resultados mostram que é preciso investir em educação tanto nos cursos básicos, técnicos e de graduação quanto em educação permanente nos serviços. 


\section{REFERÊNCIAS}

1. UNODC. World Drug Report 2014. Naciones Unidas Nueva York; 2014.

2. WHO WHO. Global status report on alcohol and health. Geneva: World Health Organization; 2011. xii, 286 p. p.

3. Carlini E, Galduróz J, Noto A, Carlini C, Oliveira L, Nappo A. II Levantamento Domiciliar sobre o uso de drogas psicotrópicas no Brasil: Envolvendo as 108 maiores cidades do país. Brasília - Distrito Federal: Centro Brasileiro de Informação sobre drogas - CEBRID; 2005.

4. Carlini E, Galduróz J, Silva A, Noto A, Fonseca A, Carlini C, et al. II Levantamento domiciliar sobre o uso de drogas psicotrópicas no Brasil: estudo envolvendo as 108 maiores cidades do país. São Paulo: Centro Brasileiro de Informações sobre Drogas Psicotrópicas, Departamento de Psicobiologia da Escola Paulista de Medicina; 2006. Available from: http://200.144.91.102/sitenovo/conteudo.aspx?cd=644.

5. Malta DC, Silva Jr JBd. O Plano de Ações Estratégicas para o Enfrentamento das Doenças Crônicas Não Transmissíveis no Brasil e a definição das metas globais para o enfrentamento dessas doenças até 2025: uma revisão. Epidemiologia e Serviços de Saúde. 2013;22(1):151-64.

6. Grittner U, Kuntsche S, Graham K, Bloomfield K. Social inequalities and gender differences in the experience of alcohol-related problems. Alcohol and alcoholism. 2012;47(5):597-605.

7. Godoy I. Prevalência de tabagismo no Brasil: medidas adicionais para o controle da doença devem ser priorizadas no Ano do Pulmão. J bras pneumol. 2010;36(1):4-5.

8. BRASIL. Lei 11.705/2008. Published at Diário Oficial da União on June 20th. 2008. 
9. Bertolote J. Glossário de álcool e drogas. Secretaria Nacional Antidrogas, Gabinete de Segurança Institucional, Governo Federal, Brasil. 2004.

10. Brasil. A Política do Ministério da Saúde para a Atenção Integral a Usuários de Álcool e outras Drogas. In: Ministério da Saúde SdAàSSC-DA, editor. 2a ed. Brasília2004.

11. PORTARIA № 1.612/GM DE 9 DE STEMBRO DE 2005, (2005).

12. PORTARIA № 1.028/GM DE 1을 DE JULHO DE 2005. Determina que as ações que visam à redução de danos sociais e à saúde, decorrentes do uso de produtos, substâncias ou drogas que causem dependência, sejam reguladas por esta Portaria., (2005).

13. PORTARIA № 384 DE 05 DE JULHO DE 2005, (2005).

14. Organização Mundial da Saúde OOP-AdS, OPAS. Relatório Sobre a Saúde no Mundo. Saúde Mental: nova concepção, nova esperança. Genebra2001.

15. PORTARIA № 4.279, DE 30 DE DEZEMBRO DE 2010, (2010).

16. PORTARIA № 3.088, DE 23 DE DEZEMBRO DE 2011. Institui a Rede de Atenção Psicossocial para pessoas com sofrimento ou transtorno mental e com necessidades decorrentes do uso de crack, álcool e outras drogas, no âmbito do Sistema Único de Saúde (SUS). (2011).

17. Brasil, dMinistério da Saúde . Secretaria de Atenção à Saúde. DAPES. Coordenação Geral de Saúde Mental ÁeOD. Saúde Mental no SUS: as novas fronteiras da Reforma Psiquiátrica. Relatório de Gestão 2007-2010. Ministério da Saúde Brasília^ eMS MS; 2011.

18. Barros S, Oliveira MAFd, Silva ALAe. Práticas inovadoras para o cuidado em saúde. Revista da Escola de Enfermagem da USP. 2007;41:8159. 
19. PORTARIA № 130, DE 26 DE JANEIRO DE 2012. Redefine o Centro de Atenção Psicossocial de Álcool e outras Drogas 24 h (CAPS AD III) e os respectivos incentivos financeiros., (2012).

20. Azevedo DMd, Miranda FANd. Práticas profissionais e tratamento ofertado nos CAPSad do município de Natal-RN: com a palavra a família. Esc Anna Nery. 2010;14(1):56-63.

21. Saúde BMd. Saúde Mental em Dados 12. Ministério da Saúde do Brasil Brasília; 2015.

22. Allport GW. Attitudes. 1935.

23. Eagly AH, Chaiken S. The psychology of attitudes: Harcourt Brace Jovanovich College Publishers; 1993.

24. Ajzen I, Fishbein M. Understanding attitudes and predicting social behaviour. 1980 .

25. Ajzen I. Attitudes, personality, and behavior: McGraw-Hill Education (UK); 2005.

26. Biblioteca Virtual em Saúde B. Descritores em Ciências da Saúde. 2015.

27. Brener L, Von Hippel W, Kippax S, Preacher KJ. Attitudes: Health Professionals. Substance Use \& Misuse. 2010;45:1007-18.

28. Teachman BA, Brownell KD. Implicit anti-fat bias among health professionals: is anyone immune? International journal of obesity. 2001.

29. Nordt C, Rössler W, Lauber C. Attitudes of mental health professionals toward people with schizophrenia and major depression. Schizophrenia bulletin. 2006;32(4):709-14.

30. Jorm AF, Korten AE, Jacomb PA, Christensen $H$, Henderson $\mathrm{S}$. Attitudes towards people with a mental disorder: a survey of the Australian public and health professionals. Australian and New Zealand Journal of Psychiatry. 1999;33(1):77-83. 
31. Day JC, Bentall RP, Roberts C, Randall F, Rogers A, Cattell D, et al. Attitudes toward antipsychotic medication: the impact of clinical variables and relationships with health professionals. Archives of General Psychiatry. $2005 ; 62(7): 717-24$

32. Soares J, Vargas Dd, Oliveira MAFd. Atitudes e conhecimentos de profissionais de saúde diante do álcool, alcoolismo e do alcoolista: levantamento da produção científica nos últimos 50 anos. SMAD Revista eletrônica saúde mental álcool e drogas. 2011;7(1):45-52.

33. Carroll J. The negative attitudes of some general nurses towards drug misusers. Nursing standard (Royal College of Nursing (Great Britain): 1987). $1994 ; 9(34): 36-8$.

34. Foster J, Onyeukwu C. The attitudes of forensic nurses to substance using service users. Journal of Psychiatric and Mental Health Nursing. 2003;10(5):578-84.

35. Chung J, Chan J, Yeung R, Wan R, Ho S. Nurses' attitude toward alcoholic patients in accident and emergency department in Hong Kong. Hong Kong College of Emergency Medicine. 2003;10(2):104-12.

36. Crothers CE, Dorrian J. Determinants of nurses' attitudes toward the care of patients with alcohol problems. ISRN nursing. 2011;2011.

37. Vargas Dd, Labate RC. Trabalhar com pacientes alcoolistas: satisfação de enfermeiros de hospital geral. Revista Gaúcha de Enfermagem. $2005 ; 26(2): 252$.

38. Vargas D, Labate RC. Clinical nurses' attitudes toward the use of alcohol and alcoholism. Revista brasileira de enfermagem. 2006;59(1):4751.

39. Vargas Dd, Luis MAV. Alcohol, alcoholism and alcohol addicts: conceptions and attitudes of nurses from district basic health centers. Revista latino-americana de enfermagem. 2008;16(SPE):543-50. 
40. Vargas Dd. Atitudes de enfermeiros de hospital geral frente às características pessoais do paciente alcoolista. Rev bras enferm. 2010;63(6):1028-34.

41. Vargas Dd. Atitudes de estudantes de enfermagem frente questões relacionadas ao álcool, alcoolismo e alcoolista. Acta paul enferm. 2011;24(5):638-44.

42. Vargas D, Bittencourt MN. Alcohol and alcoholism: attitudes of nursing students. Revista brasileira de enfermagem. 2013;66(1):84-9.

43. Vargas Dd. Reduced version of the scale of attitudes towards alcohol, alcoholism, and alcoholics: primary results. Revista da Escola de Enfermagem da USP. 2011;45(4):918-25.

44. Vargas Dd. Construct validation of the scale of attitudes toward alcohol, alcoholism and individuals with alcohol use disorders. Revista de Psiquiatria Clínica. 2014;41(4):106-11.

45. Vargas D, Oliveira MA, Duarte FA. Psychosocial care Center for Alcohol and Drugs (CAPS ad): nursing insertion and practices in São Paulo City, Brazil. Rev Lat Am Enfermagem. 20112011 Jan-Feb;19(1):115-22. PubMed PMID: 21412637. eng.

46. Vargas D, Oliveira MA, Araújo EC. [Prevalence of alcohol addiction among users of primary healthcare services in Bebedouro, São Paulo State, Brazil]. Cad Saude Publica. 2009 Aug;25(8):1711-20. PubMed PMID: 19649412. por.

47. Vargas Dd, Luis MAV. Development and validation of a scale of attitudes towards alcohol, alcoholism and alcoholics. Revista latinoamericana de enfermagem. 2008;16(5):895-902.

48. Vargas Dd, Labate RC, Costa Júnior MLd. Alcoolistas-tratar ou punir: disposição de enfermeiros de hospital geral. Rev enferm UERJ. 2003;11(2):188-92. 
49. Kantorski LP. CAPSUL-Avaliação dos CAPS da Região Sul do Brasil: relatório. Pelotas: Conselho Nacional de Desenvolvimento Científico e Tecnológico (CNPq) Ministério da Saúde. 2007.

50. Bandeira M, Pitta AMF, Mercier C. Escalas brasileiras de avaliação de satisfação (SATIS-BR) e da sobrecarga (IMPACTO-BR) da equipe técnica em serviços de saúde mental. Jornal Brasileiro de Psiquiatria [Internet]. 200011 maio 2013]; 49(4):[105-15 pp.]. Available from: http://bases.bireme.br/cgibin/wxislind.exe/iah/online/?IsisScript=iah/iah.xis\&src=google\&base=LILAC $\underline{\text { S\&lang=p\&nextAction=Ink\&exprSearch=275816\&indexSearch=ID. }}$.

51. Bandeira M, Felicio CM, Cesari L. Validation of the Perception of Change Scale - Family Version (EMP-F) as a treatment outcome measure in mental health services. Revista Brasileira de Psiquiatria. 2010;32(3):283-7.

52. Bandeira $M$, Mercier $C$, Perreault $M$, Libério MMA, Pitta AMF. Escala Brasileira de Avaliação da Satisfação dos Familiares em Serviços de Saúde Mental: SATIS-BR. Jornal Brasileiro de Psiquiatria [Internet]. 2002; 51(1):[318 pp.]. Available from: http://www.ufsj.edu.br/portalrepositorio/File/lapsam/servicomental/satisfacao familia/5-

ESCALA\%20satis-familia-completa.pdf.

53. Vargas Dd. Versão reduzida da escala de atitudes frente ao álcool, alcoolismo e ao alcoolista: resultados preliminares. Revista da Escola de Enfermagem da USP. 2011;45(4):918-25.

54. Bandeira MdB, Andrade MCR, Costa CS, Silva MAd. Percepção dos pacientes sobre o tratamento em serviços de saúde mental: validação da Escala de Mudança Percebida. Psicologia: Reflexão e Crítica. 2011;24(2):23644.

55. Bandeira M, Silva MAd. Escala de Satisfação dos Pacientes com os Serviços de Saúde Mental (SATIS-BR): estudo de validação. Jornal Brasileiro de Psiquiatria. 2012;61(3):124-32. 
56. Vargas D. A construção de uma escala de atitudes frente ao álcool, ao alcoolismo e ao alcoolista: um estudo psicométrico. Ribeirão Preto: Universidade de São Paulo; 2005.

57. Pillon S, Laranjeira R, Dunn J. Nurses' attitudes towards alcoholism: factor analysis of three commonly used scales. Sao Paulo Medical Journal. 1998;116(2):1661-6.

58. Marconi MA, Lakatos EM. Fundamentos de metodologia científica. 5ạ ed. São Paulo: Atlas; 2003.

59. Baldi B, Moore DS. The practice of statistics in the life sciences: WH Freeman; 2014.

60. White H. A heteroskedasticity-consistent covariance matrix estimator and a direct test for heteroskedasticity. Econometrica: Journal of the Econometric Society. 1980:817-38.

61. Camilo CA, Bandeira M, Leal R, Scalon JD. Avaliação da satisfação e sobrecarga em um serviço de saúde mental. Cien Saude Colet. 2012;20(1):82-92 .

62. Kantorski LP, Wetzel C, Olschowsky A, Jardim VMdR, Bielemann VdLM, Schneider JF. Avalia|ccão de quarta gera\ccão: contribui|ccões metodológicas para avalia|ccão de servi $\backslash c \cos$ de saúde mental= Fourthgeneration evaluation \%U http://www.lume.ufrgs.br/handle/10183/27379. Interface: comunica \ccão, saúde, educa\ccão Botucatu Vol 13, n 31 (out/dez 2009), p 343-355. 2009.

63. Rebouças D, Legay LF, Abelha L. Satisfação com o trabalho e impacto causado nos profissionais de serviço de saúde mental. Revista de Saúde Pública. 2007;41(2):244.

64. dos Santos Silva N, Esperidião E, Cavalcante ACG, Souza ACS, da Silva KKC. DESENVOLVIMENTO DE RECURSOS HUMANOS PARA ATUAR NOS SERVIÇOS DE SAÚDE MENTAL. Texto \& Contexto Enfermagem. 2013;22(4):1142-51. 
65. Pinikahana J, Happell B, Carta B. Mental health professionals' attitudes to drugs and substance abuse. Nursing \& health sciences. 2002;4(3):57-62.

66. Vargas Dd, Duarte FAB. Enfermeiros dos centros de atenção psicossocial em álcool e drogas (caps ad): a formação e a busca pelo conhecimento específico da área. Texto \& Contexto - Enfermagem. 2011;20:119-26.

67. Merces NPd. Atitudes de estudantes de psicologia acerca do álcool, do alcoolismo e do alcoolista: Universidade de São Paulo; 2013.

68. Rassool GH, VILLAR-LUIS M, Carraro T, Lopes G. Undergraduate nursing students' perceptions of substance use and misuse: a Brazilian position. Journal of Psychiatric and Mental Health Nursing. 2006;13(1):85-9.

69. Dorji S, Solomon P. Attitudes of health professionals toward persons with disabilities in Bhutan. Asia Pacific Disability Rehabilitation Journal. 2009;20(2):32-42.

70. Hansson L, Jormfeldt $H$, Svedberg P, Svensson B. Mental health professionals' attitudes towards people with mental illness: Do they differ from attitudes held by people with mental illness? International journal of social psychiatry. 2013;59(1):48-54.

71. Stuber JP, Rocha A, Christian A, Link BG. Conceptions of mental illness: Attitudes of mental health professionals and the general public. Psychiatric Services. 2014.

72. Memarian R, Salsali M, Vanaki Z, Ahmadi F, Hajizadeh E. Professional ethics as an important factor in clinical competency in nursing. Nursing Ethics. 2007;14(2):203-14.

73. Johansson K, Bendtsen P, Åkerlind I. Early intervention for problem drinkers: readiness to participate among general practitioners and nurses in Swedish primary health care. Alcohol and Alcoholism. 2002;37(1):38-42. 
74. Aalto $M$, Aalto $M$, Pekuri $P$, Aalto $M$, Pekuri $P$, Seppä $K$, et al. Implementation of brief alcohol intervention in primary health care: do nurses' and general practitioners' attitudes, skills and knowledge change? Drug and alcohol review. 2005;24(6):555-8.

75. Volpato LF, de Castro Meneghim M, Pereira AC, Ambrosano GMB. Planejamento da qualidade nas unidades de saúde da família, utilizando o Desdobramento da Função Qualidade (QFD) Quality planning of Family Health Units using Quality Function Deployment (QFD). Cad Saúde Pública. 2010;26(8):1561-72.

76. Bittencourt RJ, Hortale VA. A qualidade nos serviços de emergência de hospitais públicos e algumas considerações sobre a conjuntura recente no município do Rio de Janeiro. Ciênc Saúde Coletiva. 2007;12(4):929-34.

77. Serapioni $M$, da Silva MGC. Avaliação da qualidade do Programa Saúde da Família em municípios do Ceará. Uma abordagem multidimensional Evaluation of the quality of Family Healthcare Program in municipalities of Ceará. A multidimensional approach. Ciência \& Saúde Coletiva. 2011;16(11):4315-26.

78. Souza RCRd, Soares E. Perspectivas dos Enfermeiros no prisma das demandas dos usuários em ouvidoria. Rev enferm UERJ. 2010;18(3):411-6.

79. Sordi D, Lemes MR, Bagnato MHS. Subsídios para uma formaçäo profissional crítico-reflexiva na área da saúde: o desafio da virada do século. Rev latinoam enferm. 1998;6(2):83-8.

80. Munro A, Watson $\mathrm{H}$, McFadyen A. Assessing the impact of training on mental health nurses' therapeutic attitudes and knowledge about comorbidity: A randomised controlled trial. International Journal of Nursing Studies. 2007;44(8):1430-8.

81. Rocha FM, de Vargas D, de Oliveira MAF, Bittencourt MN. Cuidar de dependentes de substancias psicoativas: percepcoes dos estudantes de enfermagem. Revista da Escola de Enfermagem da USP. 2013;47(3):671-7. 
82. Rassool GH, Rawaf S. Predictors of educational outcomes of undergraduate nursing students in alcohol and drug education. Nurse Education Today. 2008;28(6):691-701.

83. AMARAL-SABADINI MB, Saitz $R$, SOUZA-FORMIGONI MLO. Do attitudes about unhealthy alcohol and other drug (AOD) use impact primary care professionals' readiness to implement AOD-related preventive care? Drug and alcohol review. 2010;29(6):655-61.

84. PORTARIA № 278, DE 27 DE FEVEREIRO DE 2014. Institui diretrizes para implementação da Política de Educação Permanente em Saúde, no âmbito do Ministério da Saúde (MS). (2014).

85. Campos CJG, Teixeira MB. O atendimento do doente mental em pronto-socorro geral: sentimentos e ações dos membros da equipe de enfermagem. Rev Esc Enferm USP. 2001;35(2):141-9.

86. Spricigo JS, Alencastre MB. The nurse from health unit and the drug user: one analysis in Biguaçu/SC. Revista latino-americana de enfermagem. 2004;12(SPE):427-32. 


\title{
ANEXOS
}

\section{ANEXO I - PARECER DO COMITÊ DE ÉTICA DA EEUSP}

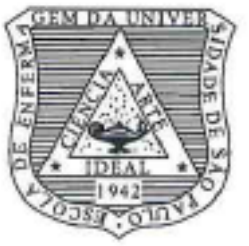

\author{
UNIVERSIDADE DE SÃO PAULO
}

ESCOLA DE ENFERMAGEM

Av. Dr. Endas de Carvalho Aguiar, 419 - CEP 05403-000

Tel.: (011) 3061-7548/8858 - Fax: (011) 3061-7548 -

Sao Paulo - SP - Brasil

o-mail: edipesq@usp.br

São Paulo, 24 de maio de 2011.

Ilm. ${ }^{2} \mathrm{Sr}^{2}$

Maria Odete Pereira

Ref: Processo n 1001/201 1/CEP-EEUSP - - SISNEP - CAAE: 0005.0.196.000-11

Prezada Senhora,

Em atenção à solicitação referente à análise do projeto "Metodologias de avaliação e medidas políticas de impacto para ações em álcool e outras drogas", a ser desenvolvido no Departamento de Enfermagem Materno-Infantil e Psiquiátrico desta Instituição, sob a responsabilidade da Professora Doutora Márcia Aparecida Ferreira de Oliveira, foi considerado aprovado pelo Comitê de Ética em Pesquisa da Escola de Enfermagem da Universidade de São Paulo (CEP/EEUSP).

Analisado sob o aspecto ético-legal, atende às exigências da Resolução n ${ }^{\circ}$ 196/96 do Conselho Nacional de Saúde.

Esclarecemos que após o término da pesquisa, os resultados obtidos deverão ser encaminhados ao CEP/EEUSP, para serem anexados ao processo.

Atenciosamente,

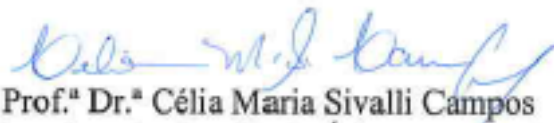

Coordenadora do Comitê de Ética em Pesquisa da

Escola de Enfermagem da Universidade de São Paulo 


\section{ANEXO II - PARECER DO COMITÊ DE ÉTICA EM PESQUISA DA SMS-SP}

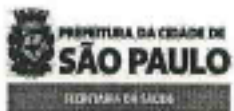

\author{
SECRETARIA MUNICIPAL DA SAÚDE \\ Comitê de Ética em Pesquisa/SMS
}

CAAE: 0145.0.196.162-11

São Paulo, 03 de Abril de 2012. PARECER N2 054/12 - CEP/SMS

IIma. Sra.

Maria Odete Pereira

Projeto de Pesquisa: Metodologias de avaliação e medidas de impacto das políticas para ações em álcool e outras drogas nos centros de atenção psicossocial álcool e outras drogas do município de São Paulo Pesquisador Responsável: Maria Odete Pereira

Instituição: Escola de Enfermagem da Universidade de São Paulo

Local onde os dados serão coletados: Todos os centros de Atenção Psicossocial - AD do município de São Paulo Patrocinador: CAPES (Programa de Pós- Doutoramento)

\section{1 - Sumário Geral do Protocolo}

Projeto de pesquisa vinculado ao "Grupo de Estudos Relacionados ao Uso Prejudicial do Álcool e Outras Drogas" - GEAD, do Programa de Pós-Graduação em Enfermagem da Escola de Enfermagem da Universidade de São Paulo, cadastrado no Conselho Nacional de Pesquisa - CNPq, que vem desenvolvendo estudos acerca dos efeitos prejudiciais do álcool e outras drogas e, busca, ao longo do tempo, novas estratégias de enfrentamento e fortalecimento da rede de assistência aos usuários de álcool e outras drogas, com ênfase na reabilitação psicossocial e inserçăo social dos mesmos, bem como a redução de danos e inclusão social.

Objetivos do Grupo de Estudos Relacionados ao Uso Prejudicial do Álcool e Outras Drogas:

- Produzir conhecimento acerca do processo de avaliação da qualidade da assistência oferecida nos Centros de Atençăo Psicossocial que atendem usuários de álcool e outras drogas - CAPS AD;

- Oferecer subsidios para a avaliação de CAPS ad no Estado de São Paulo;

- Oferecer subsidios para o ensino de enfermagem em saúde mental da Escola de Enfermagem da Universidade de São Paulo.

- Objetivo especifico deste sub-projeto.

Avaliar quantitativamente e qualitativamente os Centros de Atenção Psicossocial II ad da cidade de Săo Paulo.

Justificativa: Gerar subsidios para mudanças na atençăo em saúde mental nos CAPS ad

Metodologia:

Os dados serão coletados pela psicóloga doutoranda Paula Hayasi Pinho, do Programa de Pós-Graduação em Enfermagem da Escola de Enfermagem da USP.

A avaliação quantitativa se dará em três perspectivas.

(1)Avaliação da estrutura dos CAPS: da área fisica, dos recursos humanos e dos materiais dos CAPS ad;

Descrição da área física dos serviços (número de cómodos e sua finalidade, tamanho da construção em metros quadrado, tamanho da área interna e externa úteis para as atividades terapêuticas); descrição do mobiliário existente nos serviços; e número de funcionários e profissionais da equipe técnica.

(2) Avaliação do processo: a) da organização da atenção em saúde mental e b) do processo de trabalho.

a) A organização da atenção psicossocial, desenvolvida nos CAPS, será avaliada por meio de uma auditoria dos registros dos usuários com verificação do conteúdo relativo ao projeto terapéutico do serviço; plano terapéutico individual do usuário; normas e atividades padronizadas; sistema de referência e contra-referência; $\mathrm{e}$ registro de atendimentos em prontuários.

b) O processo de trabalho será avaliado por meio da aplicação de questionários, aos trabalhadores de saúde mental, sobre: satisfação e sobrecarga dos trabalhadores de saúde para identificar prevalência de problemas psiquiátricos menores; problemas por consumo de álcool; perfil dos trabalhadores e condições de trabalho.

(3) A avaliação quantitativa dos resultados da atenção em saúde mental será realizada por meio da aplicação de questionários aos usuários e familiares, sendo que o padrão de saúde do usuário será avaliado a partir 


\section{SECRETARIA MUNICIPAL DA SAÚDE Comitê de Ética em Pesquisa/SMS}

CAAE: 0145.0.196.162-11

da condiçăo de autonomia, inserção, cidadania, e satisfação e os familiares, com 20 a $30 \%$ dos usuários e familiares, partindo da satisfação e sobrecarga como cuidador.

A avaliaçăo qualitativa será junto aos profissionais da equipe técnica, usuários e familiares dos CAPS ad participantes.

Serão empregadas como estratégias metodológicas as técnicas de grupo focal e observação participativa.

Para a avaliação qualitativa serão empregados marcadores abstraídos a partir dos dados empíricos do projeto CAPSUL (2009) que tiveram a capacidade explicativa de indicar determinado paråmetro de avaliação. Assim, os marcadores internos a serem utilizados são:

\begin{tabular}{|c|c|}
\hline Marcadores internos & Marcadores externos \\
\hline Estrutura: - Ambiência & \multirow{3}{*}{$\begin{array}{l}\text { - Políticas públicas, gestão e articulação da rede de saú- } \\
\text { de. } \\
\text { - Relação da sociedade com o fenômeno da loucura }\end{array}$} \\
\hline $\begin{array}{l}\text { Processo de Trabalho: } \\
\text { - Atividades como suporte terapêutico } \\
\text { - Equipe, característica do trabalho } \\
\text { - Plasticidade do Serviço Inserçäo da familia }\end{array}$ & \\
\hline Resultado: - Resultado da atenção psicossocial & \\
\hline
\end{tabular}

Estratégias metodológicas: Grupo Focal e Observação Participante.

- Referência sucinta aos critérios de seleçăo (recrutomento, abordagem dos sujeitos de pesquisa, critérios de inclusø̃o e exclusöo).

Os coordenadores e membros da equipe técnica dos CAPS participantes deverão ter no mínimo seis meses de trabalho.

Para os usuários dos CAPS os critérios de inclusão serão os seguintes:

A. Individuos com idades entre 18 e 65 anos;

B. Estarem cadastrados e participando das atividades dos CAPS há no mínimo seis meses;

Serão incluídos no estudo os coordenadores, membros das equipes técnicas e usuários dos CAPS que preencherem os requisitos acima e concordarem em participar.

2-Consideraçб̄es.

Trata-se de projeto de pesquisa para exame de qualificação para obtenção do título de Doutor onde a pesquisadora pretende realizar avaliação quantitativa e qualitativa dos CAPS Ad do Estado de São Paulo.

O projeto é de grande relevância tendo em vista os escassos trabalhos sobre avaliação na área de Saúde Mental.

A avaliação quantitativa se dará em três perspectivas:

Avaliaçăo da área fisica, recursos humanos e materiais do CAPS, através de planilhas; avaliaçæ̃o dos processos de atenção à saúde através de consulta aos prontuários dos usuários; avaliação da satisfaçăo e sobrecarga dos trabalhadores através do questionário "A evaluation of the user's satisfaction scale brief - SATIS-BR"; avaliação dos resultados da atençăo em saúde mental e satisfaçăo e sobrecarga dos familiares através do questionário SATIS-OMS.

A avaliação qualitativa será realizada através de grupo focal e observação participativa em 15 CAPS Ad, um em cada regiăo administrativa do Estado de São Paulo. Tal avaliação terá como sujeitos os profissionais, os usuá. rios e seus familiares e o critério de escolha dos CAPS obedecerão aos seguintes itens: tempo de funcionamento do serviço, adequação do serviço à Portaria 336/2002, disponibilidade dos sujeitos de pesquisa para participar do estudo.

\section{- Local de Realização}

$>0$ projeto não é multicêntrico. Realizado em vários municípios do Estado de São Paulo pela mesma equipe de pesquisadores. Não informa se em todos os municipios a pesquisadora responsável pela coleta dos dados será a mesma.

Apresentação do Protocolo

* Rua General Jardim, 36 - $1^{\circ}$ andar - V. Buarque - fone: 3397.2464 - email: smscep@gipall.coth

http://www.prefeitura.sp.gov.br/cidade/secretarias/saude/comite_de_etical

Página $2 / 4$ 


\section{SECRETARIA MUNICIPAL DA SAÚDE Comitê de Ética em Pesquisa/SMS}

CAAE: 0145.0.196.162-11

$>$ A Folha de Rosto não está corretamente preenchida. As seguintes informações parecem ser incongruentes: número de sujeitos de pesquisa informado, número de CAPS AD (todos=21) e variedade de sujeitos de pesquisa (trabalhadores, usuários e familiares).

$>$ O curriculo do pesquisador responsável está de acordo com a proposta da pesquisa.

$>$ Orçamento - o projeto tem financiamento CAPES e o orçamento está descrito na pagina 2 do Anexo III - Termo de solicitação e concessão de apoio financeiro a projeto.

$>$ Cronograma da pesquisa - necessita retificaçōes

$>$ Há tratamento adequado dos dados/informações

- Avaliaçăo dos riscos e benefícios

$>$ Objetivos especíicos

$>$ Năo estăo suficientemente esclarecidos

$>$ Metodologia não está suficientemente clara.

$>$ A metodologia impőe alguma condição de desconforto ao sujeito da pesquisa, porém devidamente justificada.

$>$ Os direitos fundamentais do sujeito de pesquisa nāo estão garantidos, pois a linguagem utilizada no TCLE pode tornar seu conteúdo inacessivel. Há também a necessidade de informar no TCLE em que consiste exatamente a participaçăo: tempo de participaçăo necessário, acesso aos prontuários.

- Termo de Consentimento Livre e Esclarecido (TCLE)

$>$ É conciso e objetivo.

$>$ Está redigido na forma de convite à participação no estudo.

> A linguagem năo é adequada ao nivel sociocultural dos sujeitos de pesquisa.

$>$ Não há descrição suficiente dos procedimentos.

Há explicitaçăo das garantias referidas no item IV. 1 da Res.CNS 196/96.

$>$ Não permite uma decisão consciente do sujeito da pesquisa.

$>$ Permite a saida do sujeito de pesquisa da experimentaçăo, sem prejuizo de seus cuidados, porém apenas utiliza a palavra prejuizo e nåo fala prejuizo em quel

$>$ Há vícios a serem repelidos. Năo está explicitado no TCLE que se pretende consultar os prontuários.

$>$ Não são descritos os procedimentos e responsáveis pela obtenção do TCLE

$>$ Termos de Consentimento Livre e Esclarecido - necessitam de retificações, pois não há explicação completa e pormenorizada sobre os métodos que serão utilizados no estudo tais como grupo focal, observaçăo participativa e consulta dos prontuários.

3 - Situação do Protocolo - pendente quanto:

1) Explicar a incongruência entre as informaçōes relativas ao número de participantes ( 25 entre funcionários, usuários e familiares de usuários dos CAPS- ad), o número de CAPS -ad (todos os do município $=21$ ) e a metodologia de coleta de dados (grupo focal).

2) Explicar a frase: ....com 20 a $30 \%$ dos usuários e familiares, partindo da satisfação e sobrecarga como cuidador.

3) Quanto aos objetivos específicos: Esclarecer no objetivo específico descrito abaixo o que significa "...construçăo dos sujeitos envolvidos"

4) Quanto ao cronograma, informar mês e ano de cada etapa do projeto.

5) Adequaçōes dos TCLEs:

a) Adequar a linguagem.

b) Informar em que consiste efetivamente a participaçăo: grupo focal, resposta de questionário, observaçăo durante o serviço. Quanto tempo deverá ser disponibilizado pelas diferentes categorias de sujeitos da pesquisa.

c) Informar a pretensão de consulta aos prontuários.

d) Inserir as palavras "de seu atendimento" após a palavra prejuizo.

* Rua Ceneral Jardim, 36 - 10 andar - V. Buarque - fone: 3397.2464 - email: smscep@gmdill.com

http://www.prefeitura.sp.gov.br/cidade/secretarias/saude/comite_de_etica/

Página $3 / 4$ 


\section{SECRETARIA MUNICIPAL DA SAÚDE Comitê de Ética em Pesquisa/SMS}

CAAE: 0145.0.196.162-11

e) Informar que em caso de dúvidas ou denúnclas sobre irregularidades éticas, o sujeito de pesquisa deverá entrar em contato com o Comitê de Ética em Pesquisa da Secretaria Municipal de Saúde de São Paulo, através do telefone 33972464 ou do email smscep@gmail.com, endereço Rua General Jardim 36, 1 andar.

OBS.: Todas as pendências apontadas nas Considerações acima, foram corrigidas pelo pesquisador responsável e aprovada pelos pareceristos.

\section{4 - Situação do Protocolo - APROVADO}

Antes do inicio da coleta de dados, alertamos para a necessidade de contato com o gerente da unidade quando não foi ele quem autorizou a realização da pesquisa.

O sujeito de pesquisa (ou seu representante) e o pesquisador responsável deverão rubricar todas as folhas do Termo de Consentimento Livre e Esclarecido - TCLE apondo sua assinatura na última página do referido Termo, conforme Carta Circular no 003/2011 da CONEP/CNS.

Salientamos que o pesquisador deve desenvolver a pesquisa conforme delineada no protocolo aprovado. Eventuais modificações ou emendas ao protocolo devem ser apresentadas ao CEP de forma clara e sucinta, identificando a parte do protocolo a ser modificada e suas justificativas.

Ao pesquisador cabe manter em arquivo, sob sua guarda, por 5 anos, os dados da pesquisa, contendo fichas individuais e todos os demais documentos recomendados pelo CEP (Res. CNS 196/96 item IX.2.e)

O relatório final deve ser apresentado ao CEP, logo que o estudo estiver concluído.

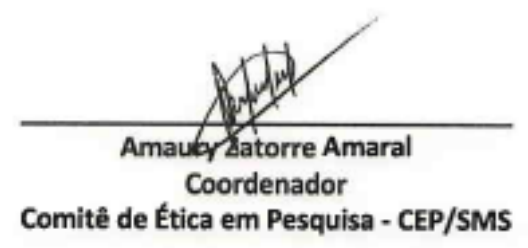

* Rua General Jardim, 36 - $1^{\circ}$ andar -V. Buarque - fone: 3397.2464 - email: smscep@gmail.com 


\section{APÊNDICES}

\section{APÊNDICE II - TERMO DE CONSENTIMENTO LIVRE E ESCLARECIDO - TRABALHADOR \\ TERMO DE CONSENTIMENTO LIVRE E ESCLARECIDO}

I - Dados de identificação:

Nome do entrevistado

II - Dados sobre a pesquisa

Título da Pesquisa: "METODOLOGIAS DE AVALIAÇÃO E MEDIDAS DE IMPACTO DAS POLÍTICAS PARA AÇÕES EM ÁLCOOL E OUTRAS DROGAS".

Pesquisadora: Maria Odete Pereira - Pós-Doutoranda no Programa de PósGraduação da Escola de Enfermagem da Universidade de São Paulo - SP e Paula Hayasi Pinho - Doutoranda no Programa de Pós-Graduação da Escola de Enfermagem da Universidade de São Paulo.

Fone: (11) 98080-4722 email: mariaodete@usp.br

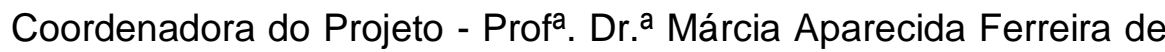
Oliveira - Professora Associada do Departamento de Enfermagem MaternoInfantil e Psiquiátrica da Escola de Enfermagem da Universidade de São Paulo.

III - Registro das explicações acerca da pesquisa ao participante:

Este estudo tem como objetivos: avaliar quantitativamente os Centros de Atenção Psicossocial II ad do Estado de São Paulo; avaliar qualitativamente os Centros de Atenção Psicossocial II ad - CAPS ad do Estado de São Paulo; estabelecer os indicadores gerais para avaliação dos CAPS ad do estado de São Paulo; elaborar instrumento de avaliação da qualidade da assistência que os CAPS ad do estado de São Paulo proporcionam aos usuários.

Você é livre para expressar suas ideias e poderá fazer questionamento acerca do estudo e sobre sua participação nele, se tiver alguma dúvida procurarei esclarecê-la em qualquer fase da pesquisa. A sua participação é voluntária, você não é obrigado (a) a participar do estudo. Você tem o direito de sair da pesquisa em qualquer etapa e em momento 
algum isto the trará prejuízos ou constrangimentos. Se você se negar a participar da pesquisa ou interrompê-la, não sofrerá nenhum prejuízo.

Os dados da presente pesquisa serão registrados e gravados; posteriormente transcritos, lidos e analisados, mas o seu nome não constará dos registros. Sua identidade não será revelada nem mesmo na fase de conclusão e publicação do estudo.

IV - Esclarecimentos dados pelo pesquisador sobre garantias do sujeito da pesquisa:

1. Acesso, a qualquer tempo, às informações sobre procedimentos, riscos e benefícios relacionados à pesquisa, inclusive para dirimir eventuais dúvidas.

2. Liberdade de retirar seu consentimento a qualquer momento e de deixar de participar do estudo, sem que isto lhe traga qualquer prejuízo.

3. Salvaguardar da confidencialidade, sigilo e privacidade.

4. Não sofrerá qualquer prejuízo, caso se negue a participar do estudo ou interrompa sua participação.

V - Consentimento Livre e Esclarecido:

"Declaro que, após convenientemente esclarecido pelo pesquisador e ter entendido o que me foi explicado, consinto em participar da presente pesquisa".

São Paulo, de de 2014

Assinatura do colaborador da Pesquisa

Assinatura do Pesquisador Responsável

Contatos do Comitê de Ética em Pesquisa da EEUSP

edipesq@usp.br 